\title{
A Molecular Tweezer for Lysine and Arginine
}

Michael Fokkens, Thomas Schrader*, ${ }^{\mathrm{a}}$ Frank-Gerrit Klärner*b

\section{Supplementary Information}

\section{Dilution titration between tweezer 1 and benzylamine hydrochloride}

Parent solution: $0.531 \mathrm{mg}(0.640 \mu \mathrm{mol})$ host 1 and

$0.083 \mathrm{mg}(0.640 \mu \mathrm{mol})$ benzylamine hydrochloride in $500 \mu \mathrm{L} \mathrm{D}_{2} \mathrm{O}$.

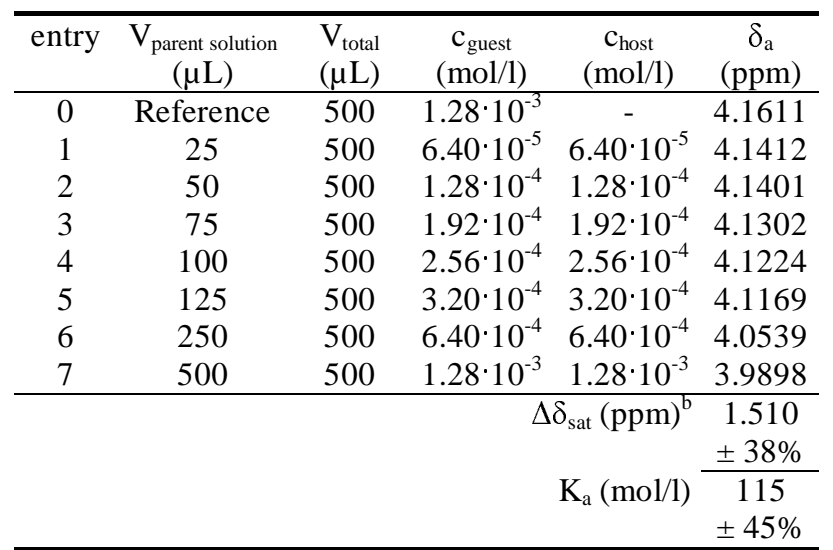

${ }^{\mathrm{b}} \Delta \delta_{\text {sat }}$ values indicate the maximum shift predicted for $100 \%$ complexation from the curve fitting.
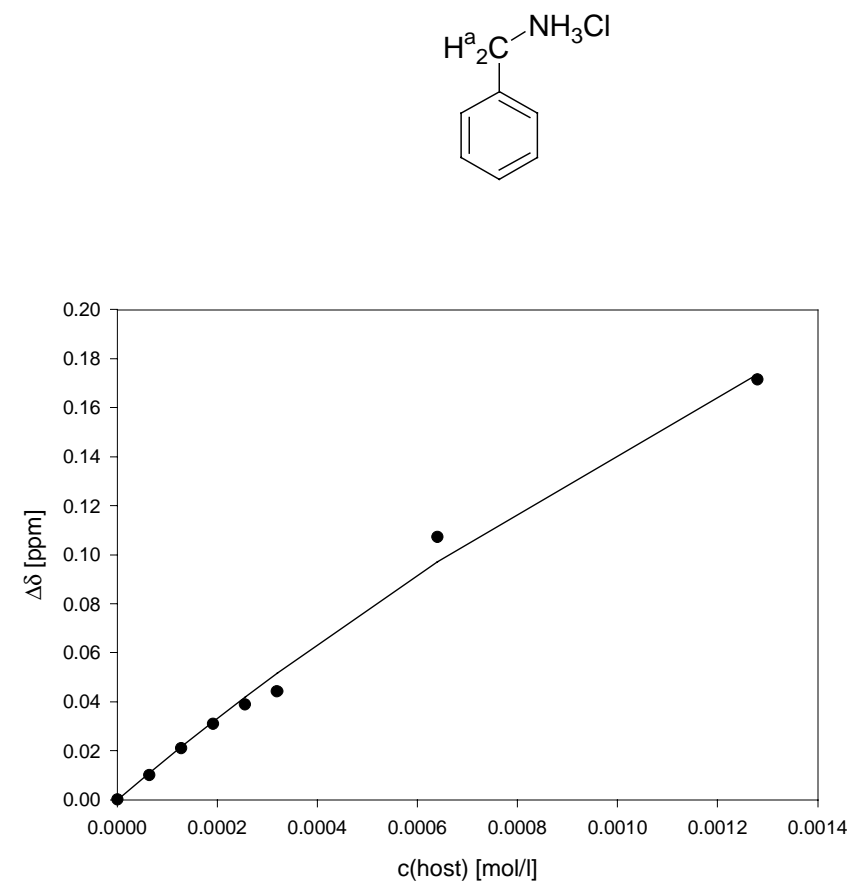


\section{Dilution titration between tweezer 1 and $n$-propylamine hydrochloride}

Parent solution: $0.600 \mathrm{mg}(0.818 \mu \mathrm{mol})$ host $\mathbf{1}$ and

$0.078 \mathrm{mg}(0.818 \mu \mathrm{mol}) n$-propylamine hydrochloride in $700 \mu \mathrm{L} \mathrm{D}_{2} \mathrm{O}$.

\begin{tabular}{|c|c|c|c|c|c|c|c|}
\hline Entry & $\begin{array}{l}\mathrm{V}_{\text {parent solution }} \\
(\mu \mathrm{L})\end{array}$ & $\begin{array}{l}\mathrm{V}_{\text {total }} \\
(\mu \mathrm{L})\end{array}$ & $\begin{array}{l}\mathrm{c}_{\text {guest }} \\
(\mathrm{mol} / \mathrm{l})\end{array}$ & $\begin{array}{c}\mathrm{c}_{\text {host }} \\
(\mathrm{mol} / \mathrm{l})\end{array}$ & $\begin{array}{c}\delta_{\mathrm{a}} \\
(\mathrm{ppm})\end{array}$ & $\begin{array}{c}\delta_{\mathrm{b}} \\
(\mathrm{ppm})\end{array}$ & $\begin{array}{c}\delta_{\mathrm{c}} \\
(\mathrm{ppm})\end{array}$ \\
\hline 0 & reference & 700 & $1.17 \cdot 10^{-3}$ & & 2.9908 & 1.7049 & 1.0022 \\
\hline 1 & 35 & 700 & $5.84 \cdot 10^{-5}$ & $5.84 \cdot 10^{-5}$ & 2.8628 & 1.5761 & 0.9136 \\
\hline 2 & 70 & 700 & $1.17 \cdot 10^{-4}$ & $1.17 \cdot 10^{-4}$ & 2.7646 & 1.4771 & 0.8444 \\
\hline 3 & 105 & 700 & $1.75 \cdot 10^{-4}$ & $1.75 \cdot 10^{-4}$ & 2.6725 & 1.3878 & 0.7803 \\
\hline 4 & 140 & 700 & $2.34 \cdot 10^{-4}$ & $2.34 \cdot 10^{-4}$ & 2.5989 & 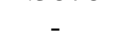 & 0.7295 \\
\hline 5 & 350 & 700 & $5.84 \cdot 10^{-4}$ & $5.84 \cdot 10^{-4}$ & 2.2508 & 0.9566 & 0.4857 \\
\hline 6 & 700 & 700 & $1.17 \cdot 10^{-3}$ & $1.17 \cdot 10^{-3}$ & 1.9649 & 0.6734 & 0.2814 \\
\hline \multirow{2}{*}{\multicolumn{5}{|c|}{$\Delta \delta_{\text {sat }}(\mathrm{ppm})$}} & 2.651 & 2.642 & 1.884 \\
\hline & & & & & $\pm 2 \%$ & $\pm 3 \%$ & $\pm 2 \%$ \\
\hline \multirow{2}{*}{\multicolumn{5}{|c|}{$\mathrm{K}_{\mathrm{a}}(\mathrm{mol} / \mathrm{l})$}} & 891 & 912 & 867 \\
\hline & & & & & $\pm 4 \%$ & $\pm 6 \%$ & $\pm 22 \%$ \\
\hline
\end{tabular}

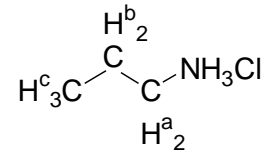

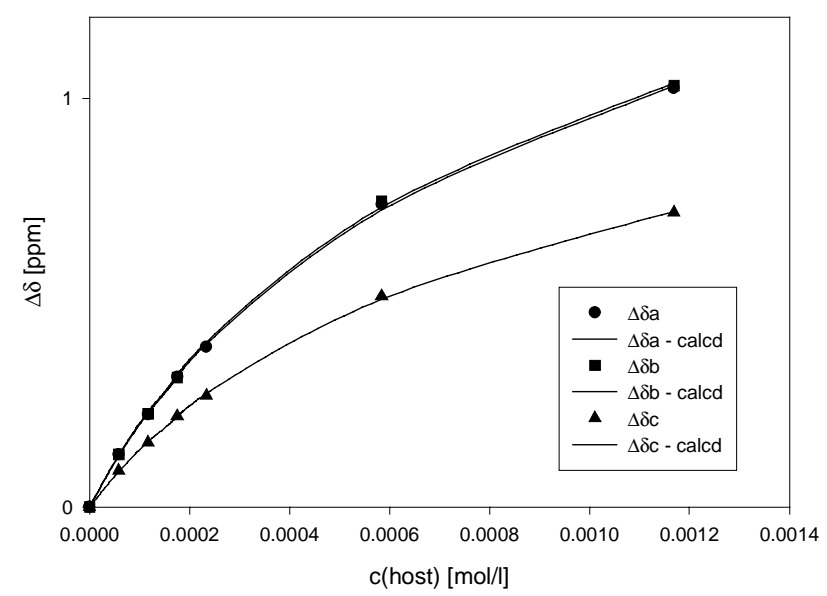




\section{Dilution titration between tweezer 1 and $n$-propylamine hydrochloride}

Parent solution: $0.539 \mathrm{mg}(0.734 \mu \mathrm{mol})$ host 1 and

$0.070 \mathrm{mg}(0.734 \mu \mathrm{mol}) n$-propylamine hydrochloride in $700 \mu \mathrm{L}$ methanol- $d_{4}$.

\begin{tabular}{|c|c|c|c|c|c|c|}
\hline entry & $\begin{array}{l}\mathrm{V}_{\text {parent solution }} \\
(\mu \mathrm{L})\end{array}$ & $\begin{array}{l}V_{\text {total }} \\
(\mu \mathrm{L})\end{array}$ & $\begin{array}{c}\mathrm{c}_{\text {guest }} \\
(\mathrm{mol} / \mathrm{l})\end{array}$ & $\begin{array}{c}\mathrm{c}_{\text {host }} \\
(\mathrm{mol} / \mathrm{l})\end{array}$ & $\begin{array}{c}\delta_{\mathrm{a}} \\
(\mathrm{ppm})\end{array}$ & $\begin{array}{c}\delta_{\mathrm{b}} \\
(\mathrm{ppm})\end{array}$ \\
\hline 0 & reference & 700 & $1.05 \cdot 10^{-3}$ & - & 2.8821 & 1.0199 \\
\hline 1 & 35 & 700 & $5.26 \cdot 10^{-5}$ & $5.26 \cdot 10^{-5}$ & 2.5940 & 0.8779 \\
\hline 2 & 70 & 700 & $1.05 \cdot 10^{-4}$ & $1.05 \cdot 10^{-4}$ & 2.4066 & 0.7771 \\
\hline 3 & 105 & 700 & $1.58 \cdot 10^{-4}$ & $1.58 \cdot 10^{-4}$ & 2.2215 & 0.6787 \\
\hline 4 & 140 & 700 & $2.10 \cdot 10^{-4}$ & $2.10 \cdot 10^{-4}$ & 2.0947 & 0.6104 \\
\hline 5 & 175 & 700 & $2.63 \cdot 10^{-4}$ & $2.63 \cdot 10^{-4}$ & 1.9788 & 0.5481 \\
\hline \multirow{2}{*}{\multicolumn{5}{|c|}{$\Delta \delta_{\text {sat }}(\mathrm{ppm})$}} & 3.451 & 2.006 \\
\hline & & & & & $\pm 6 \%$ & $\pm 5 \%$ \\
\hline \multicolumn{5}{|r|}{$\mathrm{K}_{\mathrm{a}}(\mathrm{mol} / \mathrm{l})$} & 1826 & 1534 \\
\hline & & & & & $\pm 8 \%$ & $\pm 6 \%$ \\
\hline
\end{tabular}

$\mathrm{H}_{3}^{\mathrm{b}} \mathrm{C}_{\mathrm{C}^{\mathrm{a}}} \mathrm{C}^{-\mathrm{NH}_{3} \mathrm{Cl}}$

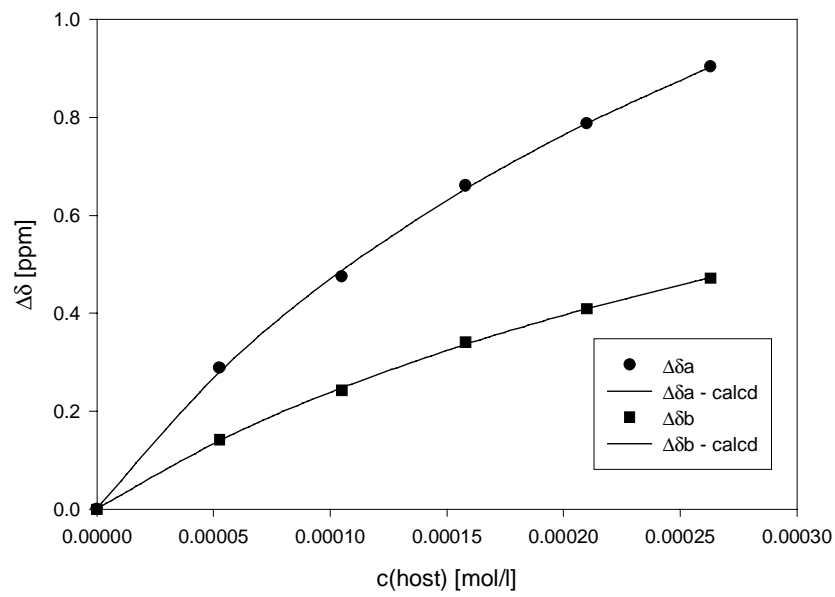




\section{Dilution titration between tweezer 1 and D-/L-adrenaline hydrochloride}

Parent solution: $0.689 \mathrm{mg}(0.938 \mu \mathrm{mol})$ host $\mathbf{1}$ and

$0.206 \mathrm{mg}(0.938 \mu \mathrm{mol}) \mathrm{D}-/ \mathrm{L}-$ adrenaline hydrochloride in $750 \mu \mathrm{L} \mathrm{D}_{2} \mathrm{O}$.

\begin{tabular}{|c|c|c|c|c|c|c|}
\hline Nr. & $\begin{array}{c}V_{\text {parent solution }} \\
(\mu \mathrm{L})\end{array}$ & $\begin{array}{l}V_{\text {total }} \\
(\mu \mathrm{L})\end{array}$ & $\begin{array}{l}\mathrm{c}_{\text {guest }} \\
(\mathrm{mol} / \mathrm{l})\end{array}$ & $\begin{array}{c}\mathrm{c}_{\text {host }} \\
(\mathrm{mol} / \mathrm{l})\end{array}$ & $\begin{array}{c}\delta_{\mathrm{a}} \\
(\mathrm{ppm})\end{array}$ & $\begin{array}{c}\delta_{\mathrm{b}} \\
(\mathrm{ppm})\end{array}$ \\
\hline 0 & Referenz & 750 & $1.25 \cdot 10^{-3}$ & - & 3.3029 & 2.7961 \\
\hline 1 & 37.5 & 750 & $6.25 \cdot 10^{-5}$ & $6.25 \cdot 10^{-5}$ & 3.2538 & 2.7462 \\
\hline 2 & 75 & 750 & $1.25 \cdot 10^{-4}$ & $1.25 \cdot 10^{-4}$ & 3.2126 & 2.7041 \\
\hline 3 & 112.5 & 750 & $1.88 \cdot 10^{-4}$ & $1.88 \cdot 10^{-4}$ & 3.1767 & 2.6611 \\
\hline 4 & 150 & 750 & $2.50 \cdot 10^{-4}$ & $2-50 \cdot 10^{-4}$ & 3.1451 & 2.6260 \\
\hline 5 & 187.5 & 750 & $3.13 \cdot 10^{-4}$ & $3.13 \cdot 10^{-4}$ & 3.1074 & 2.5875 \\
\hline 6 & 375 & 750 & $6.25 \cdot 10^{-4}$ & $6.25 \cdot 10^{-4}$ & 2.9417 & 2.4305 \\
\hline 7 & 750 & 750 & $1.17 \cdot 10^{-3}$ & $1.17 \cdot 10^{-3}$ & 2.7628 & 2.2472 \\
\hline \multirow{2}{*}{\multicolumn{5}{|c|}{$\Delta \delta_{\text {sat }}(\mathrm{ppm})$}} & 2.149 & 2.017 \\
\hline & & & & & $\pm 8 \%$ & $\pm 4 \%$ \\
\hline \multirow{2}{*}{\multicolumn{5}{|c|}{$\mathrm{K}_{\mathrm{a}}(\mathrm{mol} / \mathrm{l})$}} & 364 & 416 \\
\hline & & & & & $\pm 11 \%$ & $\pm 6 \%$ \\
\hline
\end{tabular}
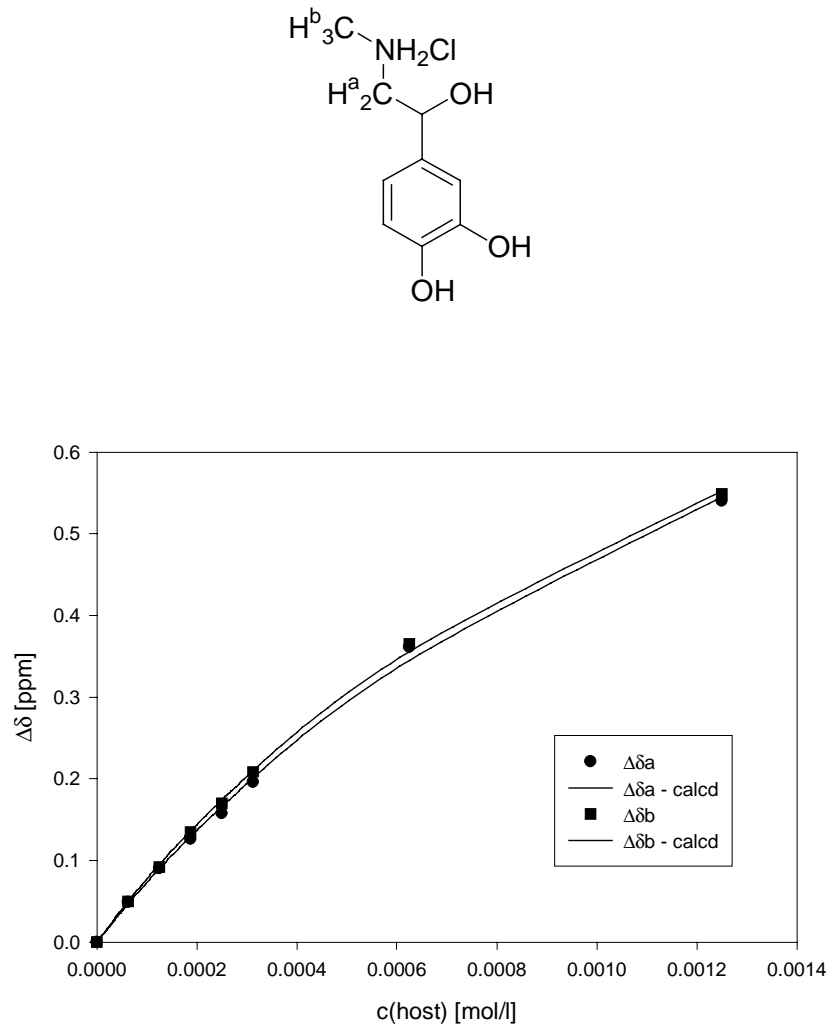


\section{Dilution titration between tweezer 1 and propanolol hydrochloride}

Parent solution: $0.633 \mathrm{mg}(0.862 \mu \mathrm{mol})$ host $\mathbf{1}$ and

$0.255 \mathrm{mg}(0.862 \mu \mathrm{mol})$ propanolol hydrochloride in $700 \mu \mathrm{L}$ methanol- $d_{4}$.

\begin{tabular}{cccccc}
\hline Entry & $\begin{array}{c}\mathrm{V}_{\text {parent solution }}(\mu \mathrm{L}) \\
(\mu \mathrm{L})\end{array}$ & $\begin{array}{c}\mathrm{V}_{\text {total }} \\
(\mathrm{mol} / \mathrm{l})\end{array}$ & $\begin{array}{c}\mathrm{c}_{\text {host }} \\
(\mathrm{mol} / \mathrm{l})\end{array}$ & $\begin{array}{c}\delta_{\mathrm{a}} \\
(\mathrm{ppm})\end{array}$ \\
\hline 0 & reference & 600 & $1.23 \cdot 10^{-3}$ & - & 1.3719 \\
1 & 60 & 600 & $1.23 \cdot 10^{-4}$ & $1.23 \cdot 10^{-4}$ & 1.2968 \\
2 & 90 & 600 & $1.85 \cdot 10^{-4}$ & $1.85 \cdot 10^{-4}$ & 1.2769 \\
3 & 120 & 600 & $2.46 \cdot 10^{-4}$ & $2.46 \cdot 10^{-4}$ & 1.2592 \\
4 & 150 & 600 & $3.08 \cdot 10^{-4}$ & $3.08 \cdot 10^{-4}$ & 1.2426 \\
5 & 600 & 600 & $1.23 \cdot 10^{-3}$ & $1.23 \cdot 10^{-3}$ & 1.1133 \\
\hline & & & $\Delta \delta_{\text {sat }}(\mathrm{ppm})$ & 0.5482 \\
& & & & $\mathrm{~K}_{\mathrm{a}}(\mathrm{mol} / \mathrm{l})$ & 1361 \\
\hline & & & & $\pm 6 \%$ \\
\hline
\end{tabular}

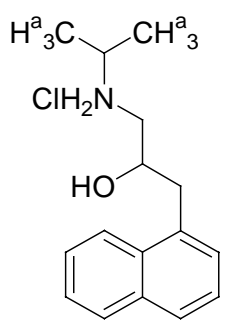




\section{Dilution titration between tweezer 1 and D-/L-noradrenaline hydrochloride}

Parent solution: $0.612 \mathrm{mg}(0.833 \mu \mathrm{mol})$ host 1 and

$0.171 \mathrm{mg}(0.833 \mu \mathrm{mol}) \mathrm{D}-/ \mathrm{L}-$ adrenaline hydrochloride in $700 \mu \mathrm{L} \mathrm{D}_{2} \mathrm{O}$.

\begin{tabular}{|c|c|c|c|c|c|}
\hline Entry & $\begin{array}{c}\mathrm{V}_{\text {parent solution }} \\
(\mu \mathrm{L})\end{array}$ & $\begin{array}{l}\mathrm{V}_{\text {total }} \\
(\mu \mathrm{L})\end{array}$ & $\begin{array}{l}\mathrm{c}_{\text {guest }} \\
(\mathrm{mol} / \mathrm{l})\end{array}$ & $\begin{array}{c}\mathrm{c}_{\text {host }} \\
(\mathrm{mol} / \mathrm{l})\end{array}$ & $\begin{array}{c}\delta_{\mathrm{a}} \\
(\mathrm{ppm})\end{array}$ \\
\hline 0 & reference & 700 & $1.25 \cdot 10^{-3}$ & - & 3.2084 \\
\hline 1 & 70 & 700 & $1.19 \cdot 10^{-5}$ & $1.19 \cdot 10^{-5}$ & 3.1918 \\
\hline 2 & 105 & 700 & $1.79 \cdot 10^{-4}$ & $1.79 \cdot 10^{-4}$ & 3.1797 \\
\hline 3 & 140 & 700 & $2.38 \cdot 10^{-4}$ & $2.38 \cdot 10^{-4}$ & 3.1741 \\
\hline 4 & 175 & 700 & $2.98 \cdot 10^{-4}$ & $2.98 \cdot 10^{-4}$ & 3.1664 \\
\hline 5 & 350 & 700 & $5.95 \cdot 10^{-4}$ & $5.95 \cdot 10^{-4}$ & 3.1225 \\
\hline 6 & 700 & 700 & $1.19 \cdot 10^{-4}$ & $1.19 \cdot 10^{-4}$ & 3.0692 \\
\hline \multicolumn{5}{|c|}{$\Delta \delta_{\text {sat }}(\mathrm{ppm})$} & $\begin{array}{l}0.9012 \\
\pm 17 \%\end{array}$ \\
\hline \multicolumn{5}{|r|}{$\mathrm{K}_{\mathrm{a}}(\mathrm{mol} / \mathrm{l})$} & $\begin{array}{c}184 \\
\pm 22 \%\end{array}$ \\
\hline
\end{tabular}
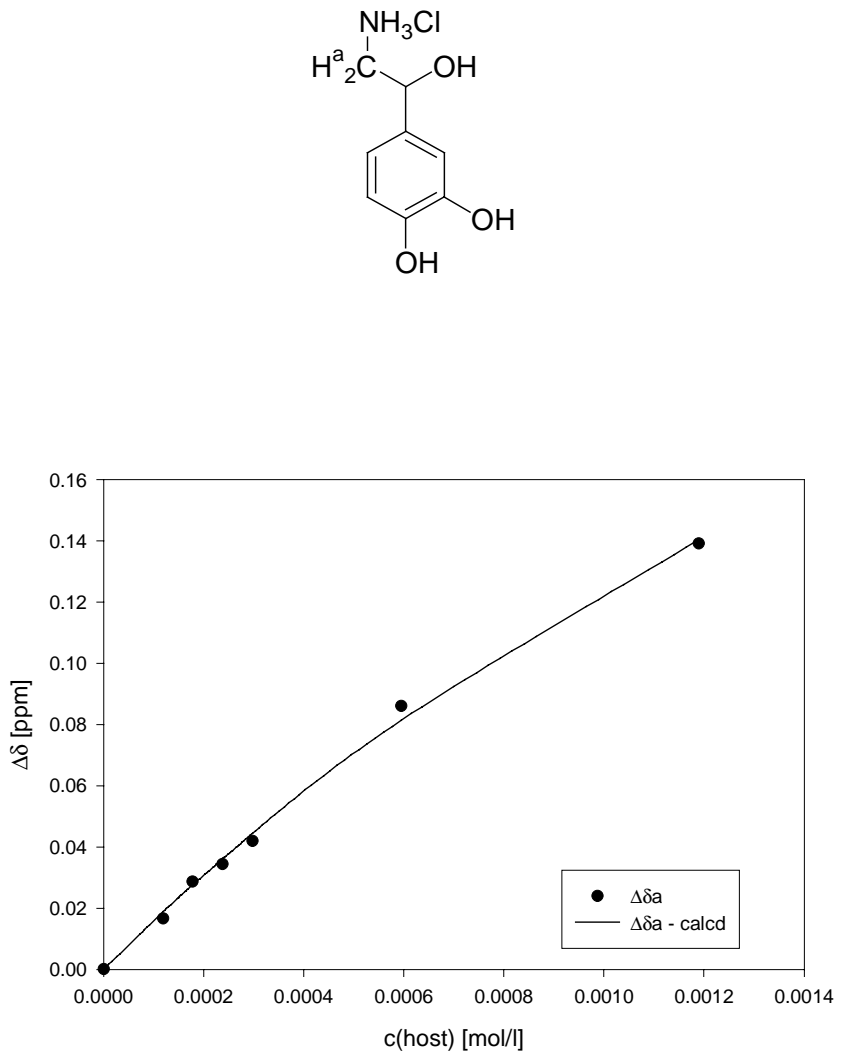


\section{Dilution titration between tweezer 1 and dopamine hydrochloride}

Parent solution: $0.603 \mathrm{mg}(0.821 \mu \mathrm{mol})$ host $\mathbf{1}$ and

$0.156 \mathrm{mg}(0.821 \mu \mathrm{mol})$ dopamine hydrochloride in $700 \mu \mathrm{L} \mathrm{D}_{2} \mathrm{O}$.

\begin{tabular}{|c|c|c|c|c|c|c|c|}
\hline Entry & $\begin{array}{c}\mathrm{V}_{\text {parent solution }} \\
(\mu \mathrm{L})\end{array}$ & $\begin{array}{l}V_{\text {total }} \\
(\mu \mathrm{L})\end{array}$ & $\begin{array}{l}\mathrm{c}_{\text {guest }} \\
(\mathrm{mol} / \mathrm{l})\end{array}$ & $\begin{array}{c}\mathrm{c}_{\text {host }} \\
(\mathrm{mol} / \mathrm{l})\end{array}$ & $\begin{array}{c}\delta_{\mathrm{a}} \\
(\mathrm{ppm})\end{array}$ & $\begin{array}{c}\delta_{\mathrm{b}} \\
(\mathrm{ppm})\end{array}$ & $\begin{array}{c}\delta_{\mathrm{c}} \\
(\mathrm{ppm})\end{array}$ \\
\hline 0 & Reference & 700 & $1.17 \cdot 10^{-3}$ & & 2.9058 & 3.2562 & 6.8726 \\
\hline 1 & 35 & 700 & $5.86 \cdot 10^{-5}$ & $5.84 \cdot 10^{-5}$ & 2.8010 & 3.1257 & 6.8433 \\
\hline 2 & 70 & 700 & $1.17 \cdot 10^{-4}$ & $1.17 \cdot 10^{-4}$ & 2.7051 & 2.9988 & 6.8217 \\
\hline 3 & 105 & 700 & $1.76 \cdot 10^{-4}$ & $1.75 \cdot 10^{-4}$ & 2.6308 & 2.9169 & 6.8012 \\
\hline 4 & 140 & 700 & $2.35 \cdot 10^{-4}$ & $2.34 \cdot 10^{-4}$ & 2.5618 & 2.8262 & 6.7897 \\
\hline 5 & 175 & 700 & $2.93 \cdot 10^{-4}$ & $2.93 \cdot 10^{-4}$ & 2.5109 & 2.7484 & 6.7655 \\
\hline 6 & 350 & 700 & $5.86 \cdot 10^{-4}$ & $5.84 \cdot 10^{-4}$ & 2.2161 & - & 6.6889 \\
\hline 7 & 700 & 700 & $1.17 \cdot 10^{-3}$ & $1.17 \cdot 10^{-3}$ & 2.0464 & 2.1757 & 6.6503 \\
\hline \multicolumn{5}{|c|}{$\Delta \delta_{\mathrm{sat}}(\mathrm{ppm})$} & 2.169 & 2.670 & 0.5658 \\
\hline \multirow{2}{*}{\multicolumn{5}{|c|}{$\mathrm{K}_{\mathrm{a}}(\mathrm{mol} / \mathrm{l})$}} & $\begin{array}{c} \pm 9 \% \\
080\end{array}$ & $\frac{ \pm 2 \%}{975}$ & $\frac{ \pm 12 \%}{988}$ \\
\hline & & & & & $+16 \%$ & $+3 \%$ & $\begin{array}{l}000 \\
+21 \%\end{array}$ \\
\hline
\end{tabular}
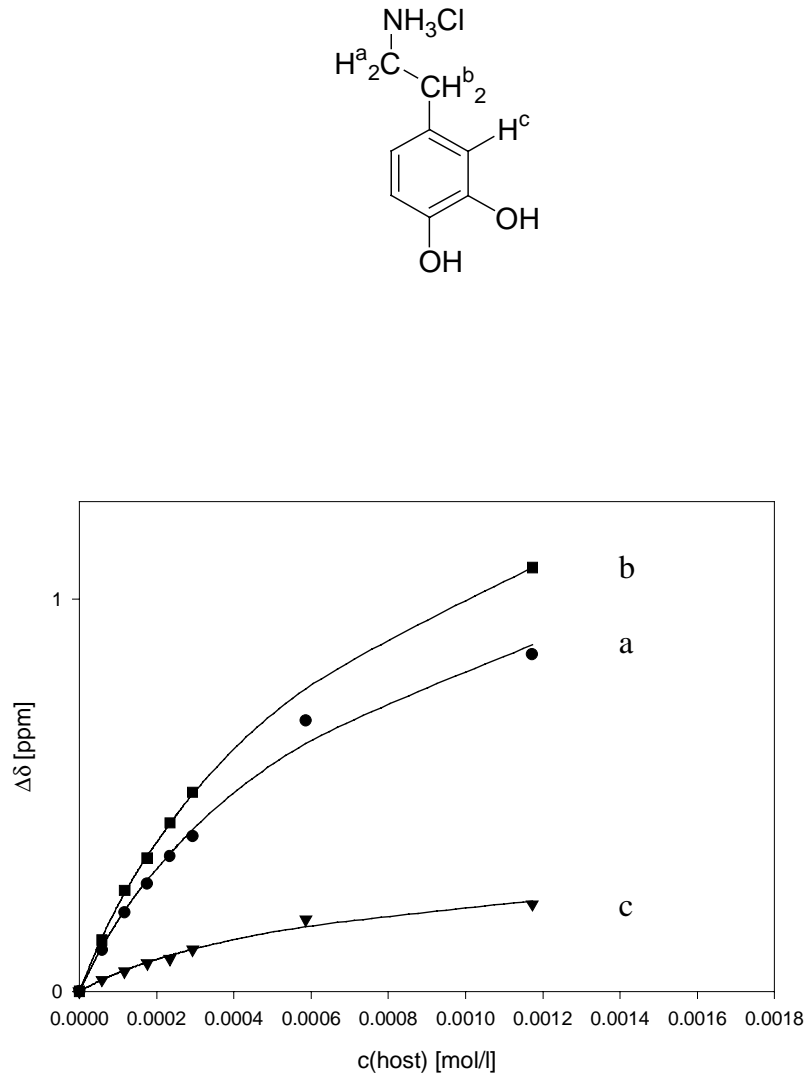
NMR titration between tweezer 1 and $N$-tosyl-(S)-arginine methyl ester hydrochloride

Host solution: $\quad 1.940 \mathrm{mg}\left(2.642 \cdot 10^{-6} \mathrm{~mol}\right)$ host 1 in $650 \mu \mathrm{L} \mathrm{D}_{2} \mathrm{O}$.

Guest solution: $\quad 0.632 \mathrm{mg}\left(1.667 \cdot 10^{-6} \mathrm{~mol}\right) \mathrm{N}$-tosyl-(S)-arginine methyl ester hydrochloride in $700 \mu \mathrm{L} \mathrm{D} \mathrm{D}_{2} \mathrm{O}$.

\begin{tabular}{|c|c|c|c|c|c|c|c|c|}
\hline Entry & $\begin{array}{l}V_{\text {guest }} \\
(\mu \mathrm{L})\end{array}$ & $\begin{array}{l}V_{\text {host }} \\
(\mu \mathrm{L})\end{array}$ & $\begin{array}{l}V_{\text {total }} \\
(\mu \mathrm{L})\end{array}$ & $\begin{array}{c}\mathrm{c}_{\text {guest }} \\
(\mathrm{mol} / \mathrm{l})\end{array}$ & $\begin{array}{c}\mathrm{C}_{\text {host }} \\
(\mathrm{mol} / \mathrm{l})\end{array}$ & $\begin{array}{c}\delta_{\mathrm{a}} \\
(\mathrm{ppm})\end{array}$ & $\begin{array}{c}\delta_{\mathrm{b}} \\
(\mathrm{ppm})\end{array}$ & $\begin{array}{c}\delta_{\mathrm{c}} \\
(\mathrm{ppm})\end{array}$ \\
\hline 0 & 70 & 0 & 600 & $2.38 \cdot 10^{-4}$ & 0 & 3.9983 & 1,8159 & 1.6721 \\
\hline 1 & 70 & 10 & 600 & $2.38 \cdot 10^{-4}$ & $5.81 \cdot 10^{-5}$ & 3.9228 & 1.6510 & 1.3134 \\
\hline 2 & 70 & 20 & 600 & $2.38 \cdot 10^{-4}$ & $1.16 \cdot 10^{-4}$ & 3.8290 & 1.4500 & 1.3177 \\
\hline 3 & 70 & 30 & 600 & $2.38 \cdot 10^{-4}$ & $1.74 \cdot 10^{-4}$ & 3.7685 & 1.3099 & 1.3099 \\
\hline 4 & 70 & 40 & 600 & $2.38 \cdot 10^{-4}$ & $2.32 \cdot 10^{-4}$ & 3.6738 & 1.1170 & 0.9724 \\
\hline 5 & 70 & 60 & 600 & $2.38 \cdot 10^{-4}$ & $3.48 \cdot 10^{-4}$ & 3.5484 & 0.8549 & 0.7000 \\
\hline 6 & 70 & 80 & 600 & $2.38 \cdot 10^{-4}$ & $4.65 \cdot 10^{-4}$ & 3.4871 & 0.7216 & 0.5734 \\
\hline 7 & 70 & 120 & 600 & $2.38 \cdot 10^{-4}$ & $6.97 \cdot 10^{-4}$ & 3.4485 & 0.6024 & 0.4638 \\
\hline 8 & 70 & 180 & 600 & $2.38 \cdot 10^{-4}$ & $1.05 \cdot 10^{-3}$ & 3.4257 & 0.5366 & 0.4042 \\
\hline \multicolumn{6}{|c|}{$\Delta \delta_{\text {sat }}(\mathrm{ppm})$} & 0.6808 & 1.547 & 1.472 \\
\hline & & & & & & $\pm 7 \%$ & $\pm 6 \%$ & $\pm 5 \%$ \\
\hline \multicolumn{6}{|r|}{$\mathrm{K}_{\mathrm{a}}(\mathrm{mol} / \mathrm{l})$} & $\begin{array}{c}7988 \\
\pm 29 \%\end{array}$ & $\begin{array}{c}6778 \\
\pm 23 \%\end{array}$ & $\begin{array}{r}8762 \\
\pm 24 \%\end{array}$ \\
\hline
\end{tabular}
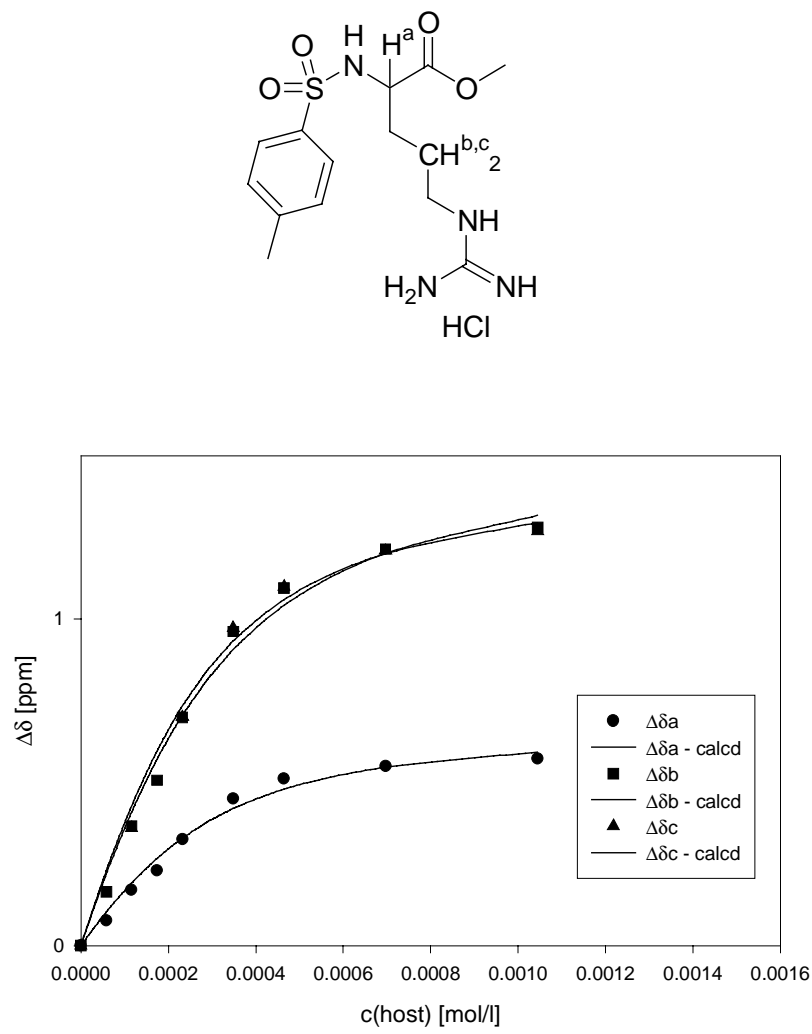
NMR titration between tweezer 1 and $N$-tosyl-(S)-arginine methyl ester hydrochloride

Host solution: $1.074 \mathrm{mg}\left(1.463 \cdot 10^{-6} \mathrm{~mol}\right)$ host 1 in $650 \mu \mathrm{L} 25 \mathrm{mmol} / 1 \mathrm{Na}_{2} \mathrm{HPO}_{4} / \mathrm{NaH}_{2} \mathrm{PO}_{4}$ buffer ( $\mathrm{pH} 7)$ in $\mathrm{D}_{2} \mathrm{O}$.

Guest solution: $0.379 \mathrm{mg}\left(1.000 \cdot 10^{-6} \mathrm{~mol}\right) \mathrm{N}$-tosyl- $(S)$-arginine methyl ester hydrochloride in $400 \mu \mathrm{L} 25 \mathrm{mmol} / 1 \mathrm{Na}_{2} \mathrm{HPO}_{4} / \mathrm{NaH}_{2} \mathrm{PO}_{4}$ buffer (pH 7) in $\mathrm{D}_{2} \mathrm{O}$.

\begin{tabular}{|c|c|c|c|c|c|c|c|c|}
\hline Entry & $\begin{array}{l}V_{\text {Guest }} \\
(\mu \mathrm{L})\end{array}$ & $\begin{array}{l}V_{\text {host }} \\
(\mu \mathrm{L})\end{array}$ & $\begin{array}{l}V_{\text {total }} \\
(\mu \mathrm{L})\end{array}$ & $\begin{array}{c}\begin{array}{c}c_{\text {guest }} \\
(\mathrm{mol} / \mathrm{l})\end{array}\end{array}$ & $\begin{array}{c}\mathrm{C}_{\text {host }} \\
(\mathrm{mol} / \mathrm{l})\end{array}$ & $\begin{array}{c}\delta_{\mathrm{a}} \\
(\mathrm{ppm})\end{array}$ & $\begin{array}{c}\delta_{\mathrm{b}} \\
(\mathrm{ppm})\end{array}$ & $\begin{array}{c}\delta_{\mathrm{c}} \\
(\mathrm{ppm})\end{array}$ \\
\hline 0 & 40 & 0 & 600 & $1.67 \cdot 10^{-4}$ & 0 & 3.9943 & 1.8119 & 1.6900 \\
\hline 1 & 40 & 10 & 600 & $1.67 \cdot 10^{-4}$ & $3.75 \cdot 10^{-5}$ & 3.9251 & 1.6726 & 1.5453 \\
\hline 2 & 40 & 20 & 600 & $1.67 \cdot 10^{-4}$ & $7.50 \cdot 10^{-5}$ & 3.8797 & 1.5819 & 1.4362 \\
\hline 3 & 40 & 30 & 600 & $1.67 \cdot 10^{-4}$ & $1.13 \cdot 10^{-4}$ & 3.8087 & 1.4060 & 1.3093 \\
\hline 4 & 40 & 40 & 600 & $1.67 \cdot 10^{-4}$ & $1.50 \cdot 10^{-4}$ & 3.7629 & 1.3121 & 1.1641 \\
\hline 5 & 40 & 50 & 600 & $1.67 \cdot 10^{-4}$ & $1.88 \cdot 10^{-4}$ & 3.7011 & 1.1953 & 1.0363 \\
\hline 6 & 40 & 60 & 600 & $1.67 \cdot 10^{-4}$ & $2.25 \cdot 10^{-4}$ & 3.6516 & 1.0913 & 0.9332 \\
\hline 7 & 40 & 160 & 600 & $1.67 \cdot 10^{-4}$ & $3.00 \cdot 10^{-4}$ & 3.6086 & 0.9144 & 0.7958 \\
\hline \multicolumn{6}{|c|}{$\Delta \delta_{\text {sat }}(\mathrm{ppm})$} & $\begin{array}{l}1.002 \\
+25 \%\end{array}$ & $\begin{array}{l}4.093 \\
+26 \%\end{array}$ & $\begin{array}{c}3.292 \\
+27 \%\end{array}$ \\
\hline \multirow{2}{*}{\multicolumn{6}{|c|}{$\mathrm{K}_{\mathrm{a}}(\mathrm{mol} / \mathrm{l})$}} & 2811 & 1077 & 1519 \\
\hline & & & & & & $\pm 44 \%$ & $\pm 36 \%$ & $\pm 40 \%$ \\
\hline
\end{tabular}
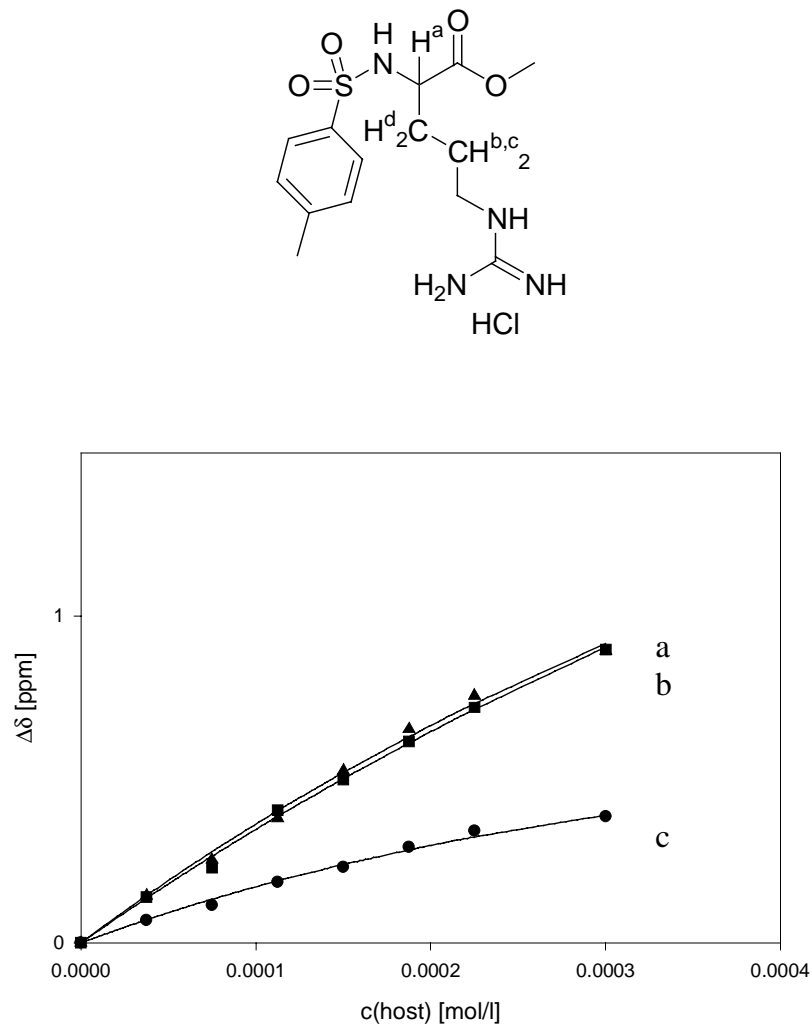
NMR titration between Tweezer 1 and $(S)$-Argininyl-(S)-glycinyl-(S)-aspartate (RGD)

Host solution: $1.084 \mathrm{mg}\left(1.477 \cdot 10^{-6} \mathrm{~mol}\right)$ host $\mathbf{1}$ in $650 \mu \mathrm{L} \mathrm{D}_{2} \mathrm{O}$.

Guest solution: $0.419 \mathrm{mg}\left(1.048 \cdot 10^{-6} \mathrm{~mol}\right) \mathrm{RGD}$ in $400 \mu \mathrm{L} \mathrm{D}_{2} \mathrm{O}$ (RGD $\left.86.5 \%\right)$.

\begin{tabular}{|c|c|c|c|c|c|c|c|c|}
\hline Entry & $\begin{array}{l}V_{\text {guest }} \\
(\mu \mathrm{L})\end{array}$ & $\begin{array}{l}V_{\text {host }} \\
(\mu \mathrm{L})\end{array}$ & $\begin{array}{l}V_{\text {total }} \\
(\mu \mathrm{L})\end{array}$ & $\begin{array}{c}\mathrm{c}_{\text {guest }} \\
(\mathrm{mol} / \mathrm{l})\end{array}$ & $\begin{array}{c}\mathrm{c}_{\text {host }} \\
(\mathrm{mol} / \mathrm{l})\end{array}$ & $\begin{array}{c}\delta_{\mathrm{a}} \\
(\mathrm{ppm})\end{array}$ & $\begin{array}{c}\Delta_{\mathrm{b}} \\
(\mathrm{ppm})\end{array}$ & $\begin{array}{c}\delta_{\mathrm{c}} \\
(\mathrm{ppm})\end{array}$ \\
\hline 0 & 40 & 0 & 600 & $1.75 \cdot 10^{-4}$ & 0 & 3.2772 & 1.9855 & 1.7361 \\
\hline 1 & 40 & 10 & 600 & $1.75 \cdot 10^{-4}$ & $3.79 \cdot 10^{-5}$ & 3.1561 & 1.9719 & 1.6872 \\
\hline 2 & 40 & 20 & 600 & $1.75 \cdot 10^{-4}$ & $7.57 \cdot 10^{-5}$ & 3.0376 & 1.9236 & 1.6124 \\
\hline 3 & 40 & 30 & 600 & $1.75 \cdot 10^{-4}$ & $1.14 \cdot 10^{-4}$ & 2.9229 & 1.9056 & 1.5528 \\
\hline 4 & 40 & 40 & 600 & $1.75 \cdot 10^{-4}$ & $1.52 \cdot 10^{-4}$ & 2.8204 & 1.8734 & 1.5010 \\
\hline 5 & 40 & 50 & 600 & $1.75 \cdot 10^{-4}$ & $1.89 \cdot 10^{-4}$ & 2.7083 & 1.8547 & 1.4488 \\
\hline 6 & 40 & 60 & 600 & $1.75 \cdot 10^{-4}$ & $2.27 \cdot 10^{-4}$ & - & 1.8289 & 1.4017 \\
\hline 7 & 40 & 80 & 600 & $1.75 \cdot 10^{-4}$ & $3.03 \cdot 10^{-4}$ & - & 1.7793 & 1.3077 \\
\hline 8 & 40 & 120 & 600 & $1.75 \cdot 10^{-4}$ & $4.54 \cdot 10^{-4}$ & 2.1092 & 1.7071 & 1.1357 \\
\hline 9 & 40 & 180 & 600 & $1.75 \cdot 10^{-4}$ & $6.82 \cdot 10^{-3}$ & - & 1.6330 & 0.7692 \\
\hline \multirow{2}{*}{\multicolumn{6}{|c|}{$\Delta \delta_{\text {sat }}(\mathrm{ppm})$}} & 4.578 & 0.8838 & 2.022 \\
\hline & & & & & & $\pm 3 \%$ & $\pm 11 \%$ & $\pm 6 \%$ \\
\hline \multirow{2}{*}{\multicolumn{6}{|c|}{$\mathrm{K}_{\mathrm{a}}(\mathrm{mol} / \mathrm{l})$}} & 836 & 1109 & 1012 \\
\hline & & & & & & $\pm 4 \%$ & $\pm 17 \%$ & $\pm 9 \%$ \\
\hline
\end{tabular}<smiles>CC(=O)OCCCCCCC(=N)NCC(=O)NC(CC(=O)O)C(=O)O</smiles>

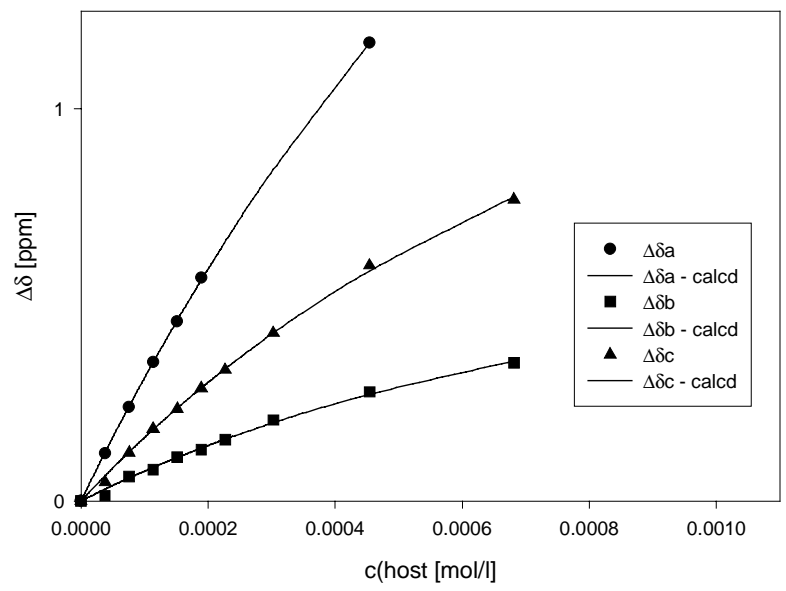




\section{NMR titration between Tweezer 1 and $(S)$-Argininyl-(S)-glycinyl-(S)-aspartate (RGD)}

Host solution: $1.006 \mathrm{mg}\left(1.370 \cdot 10^{-6} \mathrm{~mol}\right)$ host $\mathbf{1}$ in $650 \mu \mathrm{L}$ in $1000 \mu \mathrm{L} 25 \mathrm{mmol} / 1$ $\mathrm{Na}_{2} \mathrm{HPO}_{4} / \mathrm{NaH}_{2} \mathrm{PO}_{4}$ buffer ( $\mathrm{pH}$ 7) in $\mathrm{D}_{2} \mathrm{O}$.

Guest solution: $0.400 \mathrm{mg}\left(1.000 \cdot 10^{-6} \mathrm{~mol}\right) \mathrm{RGD}$ in $1000 \mu \mathrm{L}$ in $1000 \mu \mathrm{L} 25 \mathrm{mmol} / 1$

$\mathrm{Na}_{2} \mathrm{HPO}_{4} / \mathrm{NaH}_{2} \mathrm{PO}_{4}$ buffer (pH 7) in $\mathrm{D}_{2} \mathrm{O}$. (RGD 86.5\%).

\begin{tabular}{|c|c|c|c|c|c|c|c|c|}
\hline Entry & $\begin{array}{l}V_{\text {guest }} \\
(\mu \mathrm{L})\end{array}$ & $\begin{array}{l}V_{\text {host }} \\
(\mu \mathrm{L})\end{array}$ & $\begin{array}{l}V_{\text {total }} \\
(\mu \mathrm{L})\end{array}$ & $\begin{array}{c}c_{\text {guest }} \\
(\mathrm{mol} / \mathrm{l})\end{array}$ & $\begin{array}{c}\mathrm{C}_{\text {host }} \\
(\mathrm{mol} / \mathrm{l})\end{array}$ & $\begin{array}{c}\delta_{\mathrm{a}} \\
(\mathrm{ppm})\end{array}$ & $\begin{array}{c}\delta_{\mathrm{b}} \\
(\mathrm{ppm})\end{array}$ & $\begin{array}{c}\delta_{\mathrm{c}} \\
(\mathrm{ppm})\end{array}$ \\
\hline 0 & 100 & 0 & 600 & $1.67 \cdot 10^{-4}$ & 0 & 3.2682 & 1.9320 & 1.7291 \\
\hline 1 & 100 & 10 & 600 & $1.67 \cdot 10^{-4}$ & $3.51 \cdot 10^{-5}$ & 3.1562 & 1.9134 & 1.6600 \\
\hline 2 & 100 & 20 & 600 & $1.67 \cdot 10^{-4}$ & $7.03 \cdot 10^{-5}$ & 3.0608 & 1.8904 & 1.6113 \\
\hline 3 & 100 & 30 & 600 & $1.67 \cdot 10^{-4}$ & $1.05 \cdot 10^{-4}$ & 2.9693 & 1.8680 & 1.5595 \\
\hline 4 & 100 & 40 & 600 & $1.67 \cdot 10^{-4}$ & $1.41 \cdot 10^{-4}$ & 2.8637 & 1.8430 & 1.5000 \\
\hline 5 & 100 & 50 & 600 & $1.67 \cdot 10^{-4}$ & $1.76 \cdot 10^{-4}$ & 2.7773 & 1.8206 & 1.4648 \\
\hline 6 & 100 & 60 & 600 & $1.67 \cdot 10^{-4}$ & $2.11 \cdot 10^{-4}$ & 2.7037 & 1.7969 & 1.4091 \\
\hline 7 & 100 & 80 & 600 & $1.67 \cdot 10^{-4}$ & $2.81 \cdot 10^{-4}$ & - & 1.7566 & 1.3394 \\
\hline 8 & 100 & 120 & 600 & $1.67 \cdot 10^{-4}$ & $4.22 \cdot 1$ & - & 1.6894 & 1.1736 \\
\hline 9 & 100 & 200 & 600 & $1.67 \cdot 10^{-4}$ & $7.03 \cdot 10^{-3}$ & - & 1.5979 & 1.0034 \\
\hline \multirow{2}{*}{\multicolumn{6}{|c|}{$\Delta \delta_{\text {sat }}(\mathrm{ppm})$}} & 3.413 & 0.9234 & 1.502 \\
\hline & & & & & & $\pm 22 \%$ & $\pm 10 \%$ & $\pm 5 \%$ \\
\hline \multirow{2}{*}{\multicolumn{6}{|c|}{$\mathrm{K}_{\mathrm{a}}(\mathrm{mol} / \mathrm{l})$}} & 1092 & 901 & 1532 \\
\hline & & & & & & $\pm 28 \%$ & $\pm 15 \%$ & $\pm 5 \%$ \\
\hline
\end{tabular}<smiles>CC(=O)OCCCCC(=O)NCC(=O)NC(CC(=O)O)C(=O)O</smiles>

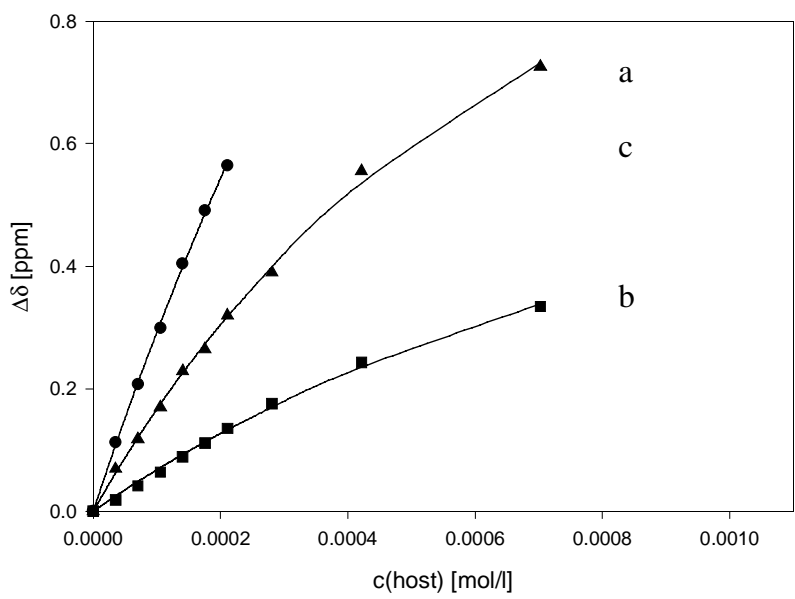


NMR titration between Tweezer 1 and $(S)$-Glycinyl-(S)-argininyl-(S)-glycinyl-(S)-glycine

Host solution: $1.135 \mathrm{mg}\left(1.546 \cdot 10^{-6} \mathrm{~mol}\right)$ host 1 in $650 \mu \mathrm{L} 25 \mathrm{mmol} / 1 \mathrm{Na}_{2} \mathrm{HPO}_{4} / \mathrm{NaH}_{2} \mathrm{PO}_{4}$ buffer ( $\mathrm{pH} 7)$ in $\mathrm{D}_{2} \mathrm{O}$.

Guest solution: $0.673 \mathrm{mg}\left(1.175 \cdot 10^{-6} \mathrm{~mol}\right)$ GRGG.2TFA in $1000 \mu \mathrm{L} 25 \mathrm{mmol} / \mathrm{l}$ $\mathrm{Na}_{2} \mathrm{HPO}_{4} / \mathrm{NaH}_{2} \mathrm{PO}_{4}$ buffer ( $\left.\mathrm{pH} 7\right)$ in $\mathrm{D}_{2} \mathrm{O}$.

\begin{tabular}{|c|c|c|c|c|c|c|c|c|}
\hline Entry & $\begin{array}{l}V_{\text {guest }} \\
(\mu \mathrm{L})\end{array}$ & $\begin{array}{l}V_{\text {host }} \\
(\mu \mathrm{L})\end{array}$ & $\begin{array}{l}V_{\text {total }} \\
(\mu \mathrm{L})\end{array}$ & $\begin{array}{c}\mathrm{c}_{\text {guest }} \\
(\mathrm{mol} / \mathrm{l})\end{array}$ & $\begin{array}{c}\mathrm{c}_{\text {host }} \\
(\mathrm{mol} / \mathrm{l})\end{array}$ & $\begin{array}{c}\delta_{\mathrm{a}} \\
(\mathrm{ppm})\end{array}$ & $\begin{array}{c}\delta_{\mathrm{b}} \\
(\mathrm{ppm})\end{array}$ & $\begin{array}{c}\delta_{\mathrm{c}} \\
(\mathrm{ppm})\end{array}$ \\
\hline 0 & 100 & 0 & 600 & $1.96 \cdot 10^{-4}$ & 0 & 3.2543 & 1.9241 & 1.8525 \\
\hline 1 & 100 & 10 & 600 & $1.96 \cdot 10^{-4}$ & $3.96 \cdot 10^{-5}$ & 3.0751 & 1.8770 & 1.7914 \\
\hline 2 & 100 & 20 & 600 & $1.96 \cdot 10^{-4}$ & $7.93 \cdot 10^{-5}$ & 2.8394 & 1.8150 & 1.7279 \\
\hline 3 & 100 & 30 & 600 & $1.96 \cdot 10^{-4}$ & $1.19 \cdot 10^{-4}$ & 2.6627 & 1.7663 & 1.6724 \\
\hline 4 & 100 & 40 & 600 & $1.96 \cdot 10^{-4}$ & $1.59 \cdot 10^{-4}$ & 2.4618 & 1.7121 & 1.6101 \\
\hline 5 & 100 & 50 & 600 & $1.96 \cdot 10^{-4}$ & $1.98 \cdot 10^{-4}$ & - & 1.6590 & 1.5521 \\
\hline 6 & 100 & 60 & 600 & $1.96 \cdot 10^{-4}$ & $2.38 \cdot 10^{-4}$ & 2.1114 & 1.6187 & 1.5015 \\
\hline 7 & 100 & 80 & 600 & $1.96 \cdot 10^{-4}$ & $3.17 \cdot 10^{-4}$ & 1.8265 & 1.5377 & \\
\hline 8 & 100 & 120 & 600 & $1.96 \cdot 10^{-4}$ & $4.76 \cdot 10^{-4}$ & - & - & 1.2746 \\
\hline 9 & 100 & 180 & 600 & $1.96 \cdot 10^{-4}$ & $7.13 \cdot 10^{-3}$ & - & 1.1964 & 1.0569 \\
\hline \multirow{2}{*}{\multicolumn{6}{|c|}{$\Delta \delta_{\text {sat }}(\mathrm{ppm})$}} & 7.461 & 2.213 & 2.058 \\
\hline & & & & & & $\pm 15 \%$ & $\pm 4 \%$ & $\pm 7 \%$ \\
\hline \multicolumn{6}{|r|}{$\mathrm{K}_{\mathrm{a}}(\mathrm{mol} / \mathrm{l})$} & $\begin{array}{c}857 \\
\pm 20 \%\end{array}$ & $\begin{array}{r}755 \\
\pm 5 \%\end{array}$ & $\begin{array}{c}972 \\
\pm 10 \%\end{array}$ \\
\hline
\end{tabular}<smiles>N=C(N)NCCCC(NC(=O)CN)C(=O)NCC(=O)NCC(=O)O</smiles>

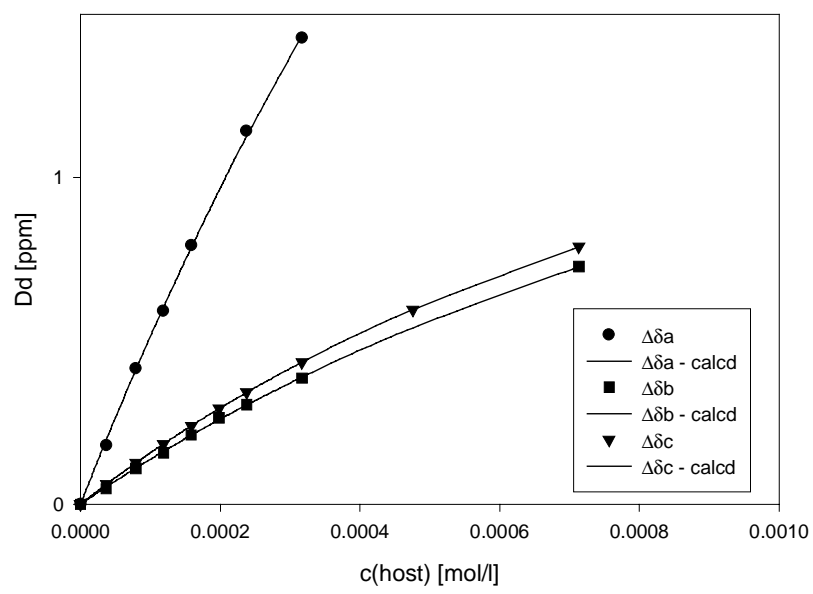




\section{NMR titration between Tweezer 1 and (S)-Lysinyl-(S)-alaninyl-(S)-alanine (KAA)}

Host solution: $0.878 \mathrm{mg}\left(1.196 \cdot 10^{-6} \mathrm{~mol}\right)$ host 1 in $650 \mu \mathrm{L} 25 \mathrm{mmol} / 1 \mathrm{Na}_{2} \mathrm{HPO}_{4} / \mathrm{NaH}_{2} \mathrm{PO}_{4}$ buffer ( $\mathrm{pH} 7)$ in $\mathrm{D}_{2} \mathrm{O}$.

Guest solution: $0.406 \mathrm{mg}\left(1.000 \cdot 10^{-6} \mathrm{~mol}\right) \mathrm{KAA} \cdot \mathrm{CH}_{3} \mathrm{COOH}$ in $200 \mu \mathrm{L} 25 \mathrm{mmol} / \mathrm{l}$ $\mathrm{Na}_{2} \mathrm{HPO}_{4} / \mathrm{NaH}_{2} \mathrm{PO}_{4}$ buffer (pH 7) in $\mathrm{D}_{2} \mathrm{O}(\mathrm{KAA} 71 \%)$.

\begin{tabular}{|c|c|c|c|c|c|c|c|}
\hline Entry & $\begin{array}{l}V_{\text {guest }} \\
(\mu \mathrm{L})\end{array}$ & $\begin{array}{l}V_{\text {host }} \\
(\mu \mathrm{L})\end{array}$ & $\begin{array}{l}V_{\text {total }} \\
(\mu \mathrm{L})\end{array}$ & $\begin{array}{c}\mathrm{c}_{\text {guest }} \\
(\mathrm{mol} / \mathrm{l})\end{array}$ & $\begin{array}{c}\mathrm{C}_{\text {host }} \\
(\mathrm{mol} / \mathrm{l})\end{array}$ & $\begin{array}{c}\delta_{\mathrm{a}} \\
(\mathrm{ppm}) \\
\end{array}$ & $\begin{array}{c}\delta_{\mathrm{b}} \\
(\mathrm{ppm})\end{array}$ \\
\hline 0 & 20 & 0 & 600 & $1.64 \cdot 10^{-4}$ & 0 & 3.9096 & 1.8894 \\
\hline 1 & 20 & 10 & 600 & $1.64 \cdot 10^{-4}$ & $3.69 \cdot 10^{-5}$ & 3.8994 & 1.8557 \\
\hline 2 & 20 & 20 & 600 & $1.64 \cdot 10^{-4}$ & $7.93 \cdot 10^{-5}$ & 3.8924 & 1.8302 \\
\hline 3 & 20 & 30 & 600 & $1.64 \cdot 10^{-4}$ & $1.19 \cdot 10^{-4}$ & 3.8841 & 1.8112 \\
\hline 4 & 20 & 40 & 600 & $1.64 \cdot 10^{-4}$ & $1.59 \cdot 10^{-4}$ & 3.8765 & 1.7807 \\
\hline 5 & 20 & 50 & 600 & $1.64 \cdot 10^{-4}$ & $1.98 \cdot 10^{-4}$ & 3.8702 & 1.7622 \\
\hline 6 & 20 & 60 & 600 & $1.64 \cdot 10^{-4}$ & $2.38 \cdot 10^{-4}$ & 3.8619 & 1.7298 \\
\hline 7 & 20 & 80 & 600 & $1.64 \cdot 10^{-4}$ & $3.17 \cdot 10^{-4}$ & 3.8466 & 1.6910 \\
\hline 8 & 20 & 120 & 600 & $1.64 \cdot 10^{-4}$ & $4.76 \cdot 10^{-4}$ & 3.8282 & 1.6166 \\
\hline 9 & 20 & 200 & 600 & $1.64 \cdot 10^{-4}$ & $7.13 \cdot 10^{-3}$ & 3.7913 & 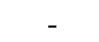 \\
\hline \multicolumn{6}{|c|}{$\Delta \delta_{\text {sat }}(\mathrm{ppm})$} & 0.2920 & 1.030 \\
\hline \multirow{2}{*}{\multicolumn{6}{|c|}{$\mathrm{K}_{\mathrm{a}}(\mathrm{mol} / \mathrm{l})$}} & 1242 & 1116 \\
\hline & & & & & & $\pm 9 \%$ & $\pm 19 \%$ \\
\hline
\end{tabular}
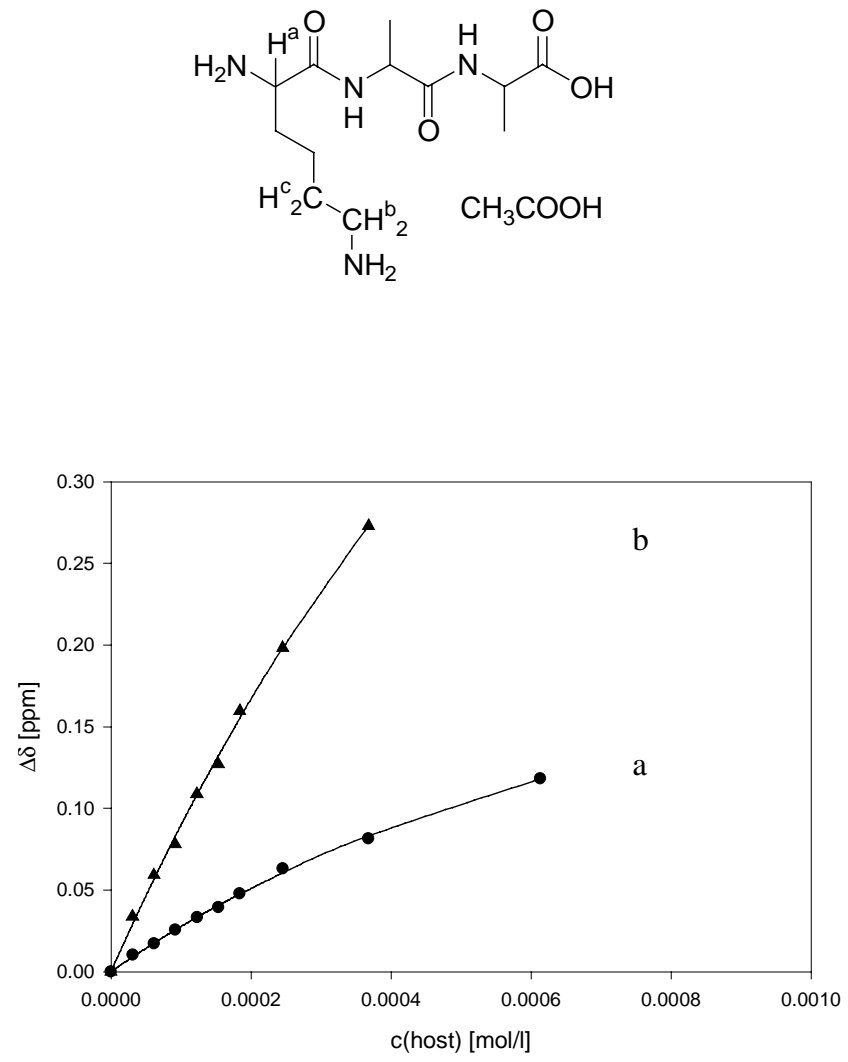
NMR titration between Tweezer 1 and tert.-Butyloxycarbonyl-(S)-histidine methyl ester

Host solution: $1.022 \mathrm{mg}\left(1.392 \cdot 10^{-6} \mathrm{~mol}\right)$ host 1 in $650 \mu \mathrm{L} 25 \mathrm{mmol} / 1 \mathrm{Na}_{2} \mathrm{HPO}_{4} / \mathrm{NaH}_{2} \mathrm{PO}_{4}$ buffer ( $\mathrm{pH} 7)$ in $\mathrm{D}_{2} \mathrm{O}$.

Guest solution: $0.295 \mathrm{mg}\left(1.094 \cdot 10^{-6} \mathrm{~mol}\right)$ tert.-Butyloxycarbonyl- $(S)$-histidine methyl ester in $500 \mu \mathrm{L} 25 \mathrm{mmol} / 1 \mathrm{Na}_{2} \mathrm{HPO}_{4} / \mathrm{NaH}_{2} \mathrm{PO}_{4}$ buffer $(\mathrm{pH} 7)$ in $\mathrm{D}_{2} \mathrm{O}$.

\begin{tabular}{|c|c|c|c|c|c|c|c|c|}
\hline Entry & $\begin{array}{l}V_{\text {guest }} \\
(\mu \mathrm{L})\end{array}$ & $\begin{array}{l}V_{\text {host }} \\
(\mu \mathrm{L})\end{array}$ & $\begin{array}{l}V_{\text {total }} \\
(\mu \mathrm{L})\end{array}$ & $\begin{array}{c}\mathrm{c}_{\text {guest }} \\
(\mathrm{mol} / \mathrm{l})\end{array}$ & $\begin{array}{c}\mathrm{c}_{\text {host }} \\
(\mathrm{mol} / \mathrm{l})\end{array}$ & $\begin{array}{c}\delta_{\mathrm{a}} \\
(\mathrm{ppm})\end{array}$ & $\begin{array}{c}\delta_{\mathrm{b}} \\
(\mathrm{ppm})\end{array}$ & $\begin{array}{c}\delta_{\mathrm{c}} \\
(\mathrm{ppm})\end{array}$ \\
\hline 0 & 100 & 0 & 600 & $1.82 \cdot 10^{-4}$ & 0 & 7.0658 & 3.1722 & 3.0421 \\
\hline 1 & 100 & 10 & 600 & $1.82 \cdot 10^{-4}$ & $3.57 \cdot 10^{-5}$ & 6.9926 & 3.1545 & 3.0376 \\
\hline 2 & 100 & 20 & 600 & $1.82 \cdot 10^{-4}$ & $7.14 \cdot 10^{-5}$ & 6.9124 & 3.1406 & 3.0238 \\
\hline 3 & 100 & 30 & 600 & $1.82 \cdot 10^{-4}$ & $1.07 \cdot 10^{-4}$ & - & 3.1254 & 3.0054 \\
\hline 4 & 100 & 40 & 600 & $1.82 \cdot 10^{-4}$ & $1.43 \cdot 10^{-4}$ & 6.7555 & 3.1128 & 2.9909 \\
\hline 5 & 100 & 50 & 600 & $1.82 \cdot 10^{-4}$ & $1.79 \cdot 10^{-4}$ & 6.6920 & 3.0995 & 2.9764 \\
\hline 6 & 100 & 60 & 600 & $1.82 \cdot 10^{-4}$ & $2.14 \cdot 10^{-4}$ & 6.6162 & 3.0837 & 2.9606 \\
\hline 7 & 100 & 80 & 600 & $1.82 \cdot 10^{-4}$ & $2.86 \cdot 10^{-4}$ & 6.5057 & 3.0604 & 2.9366 \\
\hline 8 & 100 & 120 & 600 & $1.82 \cdot 10^{-4}$ & $4.28 \cdot 10^{-4}$ & 6.2708 & 3.0124 & 2.8905 \\
\hline 9 & 100 & 180 & 600 & $1.82 \cdot 10^{-4}$ & $7.14 \cdot 10^{-4}$ & 6.8932 & 2.9461 & 2.8299 \\
\hline \multirow{2}{*}{\multicolumn{6}{|c|}{$\Delta \delta_{\text {sat }}(\mathrm{ppm})$}} & 3.764 & 0.6543 & 0.7925 \\
\hline & & & & & & $\pm 4 \%$ & $\pm 5 \%$ & $\pm 24 \%$ \\
\hline \multirow{2}{*}{\multicolumn{6}{|c|}{$\mathrm{K}_{\mathrm{a}}(\mathrm{mol} / \mathrm{l})$}} & 688 & 817 & 565 \\
\hline & & & & & & $\pm 5 \%$ & $\pm 7 \%$ & $\pm 33 \%$ \\
\hline
\end{tabular}
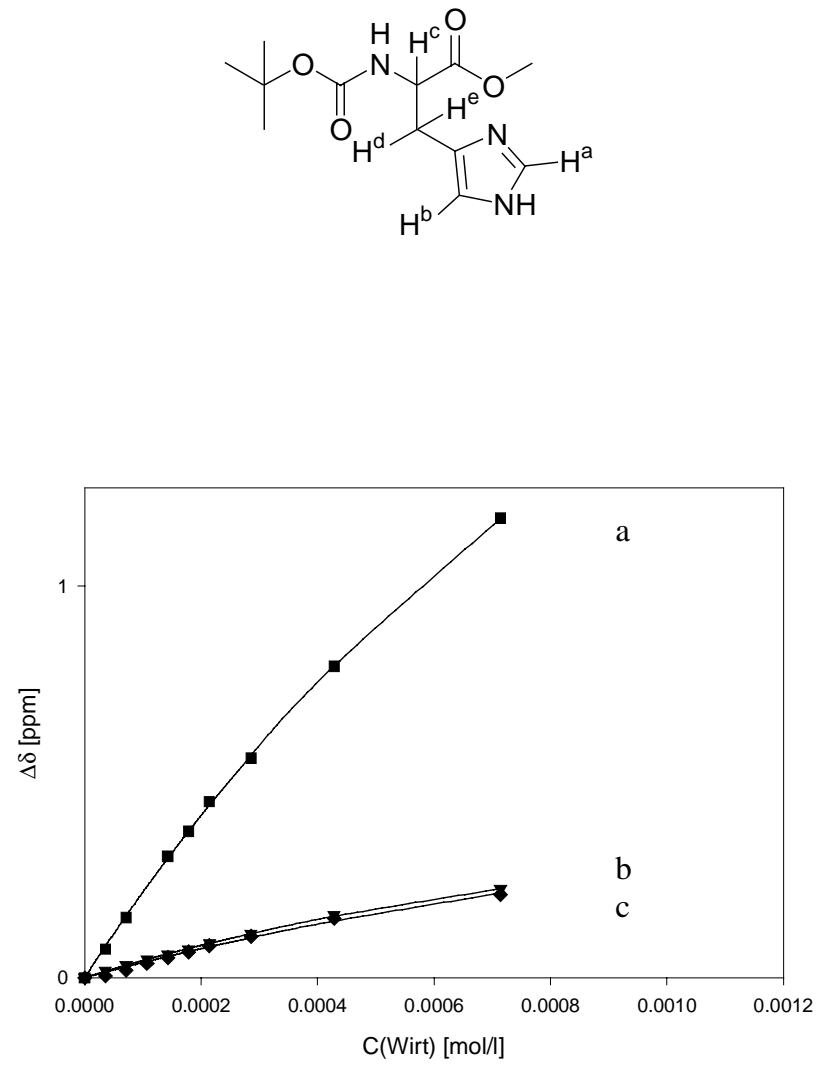


\section{Dilution titration between tweezer 1 and acetyl-(S)-lysine methyl ester hydrochloride}

Parent solution: $0.642 \mathrm{mg}(0.875 \mu \mathrm{mol})$ host 1 and

$0.208 \mathrm{mg}(0.875 \mu \mathrm{mol})$ acetyl- $(S)$-lysine methyl ester hydrochloride in $700 \mu \mathrm{L}$ $\mathrm{D}_{2} \mathrm{O}$.

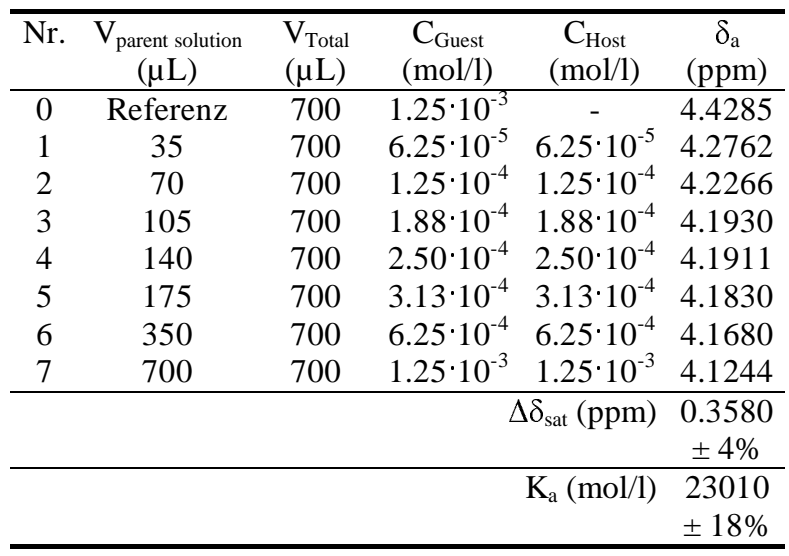
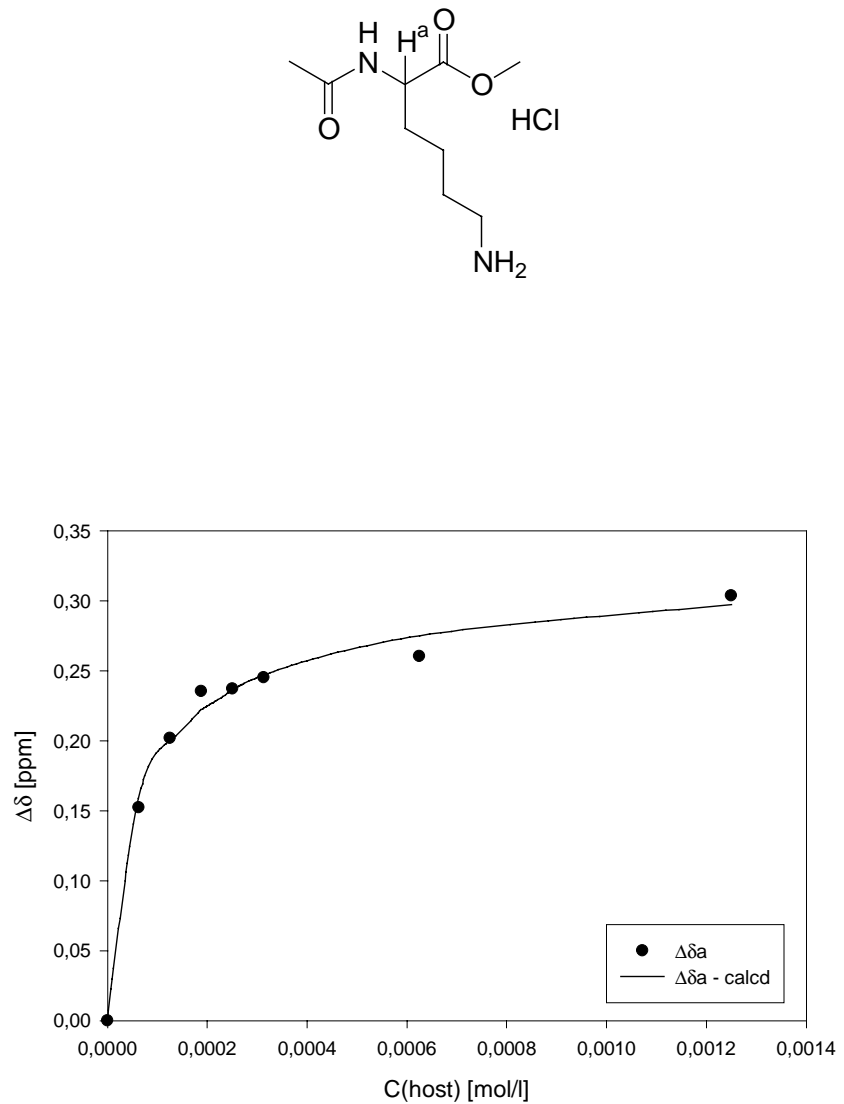


\section{NMR titration between tweezer 1 and Acetyl-(S)-lysine methyl ester hydrochloride}

Host solution: $1.130 \mathrm{mg}\left(1.540 \cdot 10^{-6} \mathrm{~mol}\right)$ host 1 in $650 \mu \mathrm{L} 25 \mathrm{mmol} / 1 \mathrm{Na}_{2} \mathrm{HPO}_{4} / \mathrm{NaH}_{2} \mathrm{PO}_{4}$ buffer ( $\mathrm{pH} 7)$ in $\mathrm{D}_{2} \mathrm{O}$.

Guest solution: $0.239 \mathrm{mg}\left(1.001 \cdot 10^{-6} \mathrm{~mol}\right)$ Acetyl- $(S)$-lysine methyl ester hydrochloride in $500 \mu \mathrm{L} 25 \mathrm{mmol} / 1 \mathrm{Na}_{2} \mathrm{HPO}_{4} / \mathrm{NaH}_{2} \mathrm{PO}_{4}$ buffer (pH 7) in $\mathrm{D}_{2} \mathrm{O}$.

\begin{tabular}{|c|c|c|c|c|c|c|c|c|}
\hline Entry & $\begin{array}{l}\mathrm{V}_{\text {guest }} \\
(\mu \mathrm{L})\end{array}$ & $\begin{array}{l}V_{\text {host }} \\
(\mu \mathrm{L})\end{array}$ & $\begin{array}{l}\mathrm{V}_{\text {total }} \\
(\mu \mathrm{L})\end{array}$ & $\begin{array}{c}\mathrm{c}_{\text {guest }} \\
(\mathrm{mol} / \mathrm{l})\end{array}$ & $\begin{array}{c}\mathrm{c}_{\text {host }} \\
(\mathrm{mol} / \mathrm{l})\end{array}$ & $\begin{array}{c}\delta_{\mathrm{a}} \\
(\mathrm{ppm})\end{array}$ & $\begin{array}{c}\delta_{\mathrm{b}} \\
(\mathrm{ppm})\end{array}$ & $\begin{array}{c}\delta_{\mathrm{c}} \\
(\mathrm{ppm})\end{array}$ \\
\hline 0 & 50 & 0 & 600 & $1.67 \cdot 10^{-4}$ & 0 & 4.4199 & 1.9278 & 1.8000 \\
\hline 1 & 50 & 10 & 600 & $1.67 \cdot 10^{-4}$ & $3.42 \cdot 10^{-5}$ & 4.3837 & 1.8238 & 1.6960 \\
\hline 2 & 50 & 20 & 600 & $1.67 \cdot 10^{-4}$ & $6.84 \cdot 10^{-5}$ & 4.3250 & 1.6714 & 1.5572 \\
\hline 3 & 50 & 30 & 600 & $1.67 \cdot 10^{-4}$ & $1.03 \cdot 10^{-4}$ & 4.2994 & 1.5865 & - \\
\hline 4 & 50 & 40 & 600 & $1.67 \cdot 10^{-4}$ & $1.37 \cdot 10^{-4}$ & 4.2627 & & - \\
\hline 5 & 50 & 60 & 600 & $1.67 \cdot 10^{-4}$ & $2.05 \cdot 10^{-4}$ & 4.1981 & 1.2892 & 1.1921 \\
\hline 6 & 50 & 80 & 600 & $1.67 \cdot 10^{-4}$ & $2.74 \cdot 10^{-4}$ & - & 1.1774 & 1.0718 \\
\hline 7 & 50 & 120 & 600 & $1.67 \cdot 10^{-4}$ & $4.10 \cdot 10^{-4}$ & 4.0905 & 0.9978 & 0.9007 \\
\hline 8 & 50 & 200 & 600 & $1.67 \cdot 10^{-4}$ & $6.16 \cdot 10^{-3}$ & 4.0442 & 0.8682 & 0.7963 \\
\hline \multirow{2}{*}{\multicolumn{6}{|c|}{$\Delta \delta_{\text {sat }}(\mathrm{ppm})$}} & 0.5677 & 1.572 & 1.454 \\
\hline & & & & & & $\pm 8 \%$ & $\pm 8 \%$ & $\pm 10 \%$ \\
\hline \multicolumn{6}{|r|}{$\mathrm{K}_{\mathrm{a}}(\mathrm{mol} / \mathrm{l})$} & 3993 & 4295 & 4730 \\
\hline
\end{tabular}
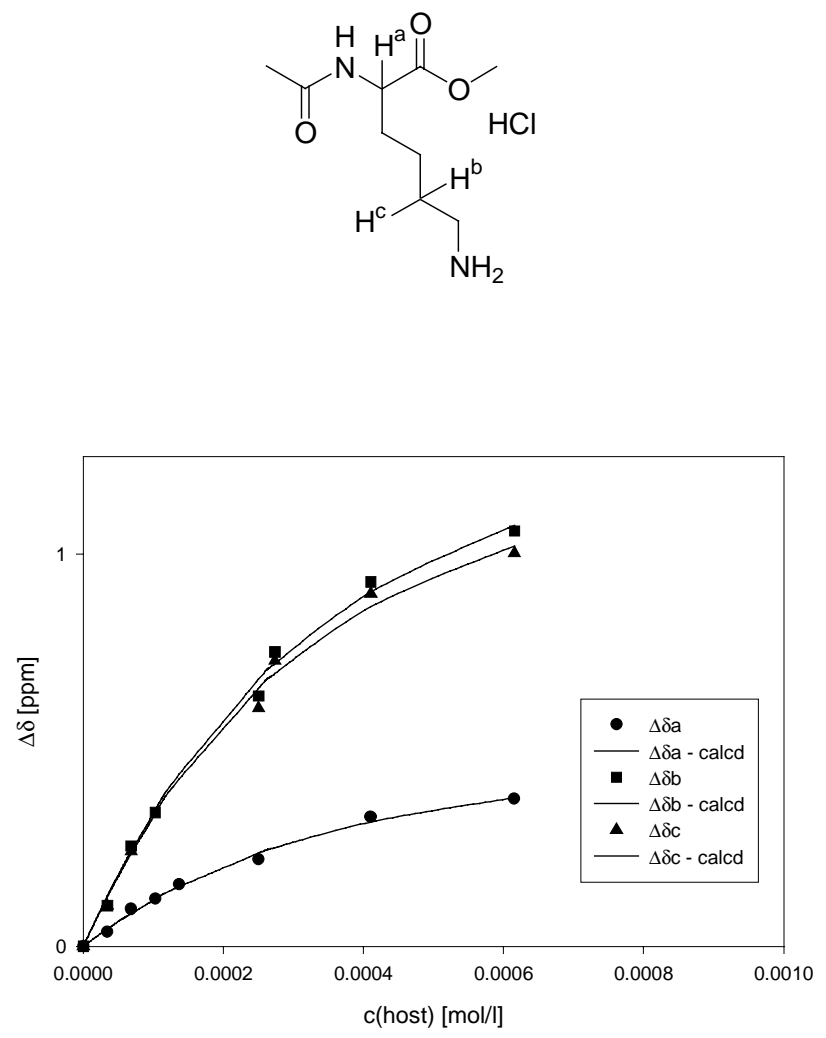


\section{NMR titration between tweezer 1 and $(S)$-lysine hydrochloride}

Host solution: $1.130 \mathrm{mg}\left(1.629 \cdot 10^{-6} \mathrm{~mol}\right)$ host 1 in $650 \mu \mathrm{L} 25 \mathrm{mmol} / \mathrm{l} \mathrm{Na} \mathrm{HPO}_{4} / \mathrm{NaH}_{2} \mathrm{PO}_{4}$ buffer ( $\mathrm{pH} 7)$ in $\mathrm{D}_{2} \mathrm{O}$.

Guest solution: $0,228 \mathrm{mg}\left(1.250 \cdot 10^{-6} \mathrm{~mol}\right)(S)$-lysine hydrochloride in $1000 \mu \mathrm{L} 25 \mathrm{mmol} / 1$ $\mathrm{Na}_{2} \mathrm{HPO}_{4} / \mathrm{NaH}_{2} \mathrm{PO}_{4}$ buffer (pH 7) in $\mathrm{D}_{2} \mathrm{O}$.

\begin{tabular}{|c|c|c|c|c|c|c|c|}
\hline Entry & $\begin{array}{l}V_{\text {guest }} \\
(\mu \mathrm{L})\end{array}$ & $\begin{array}{l}V_{\text {host }} \\
(\mu \mathrm{L})\end{array}$ & $\begin{array}{l}V_{\text {total }} \\
(\mu \mathrm{L})\end{array}$ & $\begin{array}{c}\mathrm{c}_{\text {guest }} \\
(\mathrm{mol} / \mathrm{l})\end{array}$ & $\begin{array}{c}\mathrm{c}_{\text {host }} \\
(\mathrm{mol} / \mathrm{l})\end{array}$ & $\begin{array}{c}\delta_{\mathrm{a}} \\
(\mathrm{ppm})\end{array}$ & $\begin{array}{c}\delta_{\mathrm{b}} \\
(\mathrm{ppm})\end{array}$ \\
\hline 0 & 100 & 0 & 600 & $2.08 \cdot 10^{-4}$ & 0 & 3.7823 & 1.9336 \\
\hline 1 & 100 & 10 & 600 & $2.08 \cdot 10^{-4}$ & $4.18 \cdot 10^{-5}$ & 3.7713 & 1.8996 \\
\hline 2 & 100 & 20 & 600 & $2.08 \cdot 10^{-4}$ & $8.35 \cdot 10^{-5}$ & 3.7624 & \\
\hline 3 & 100 & 30 & 600 & $2.08 \cdot 10^{-4}$ & $1.25 \cdot 10^{-4}$ & 3.7473 & 1.8279 \\
\hline 4 & 100 & 40 & 600 & $2.08 \cdot 10^{-4}$ & $1.67 \cdot 10^{-4}$ & 3.7445 & 1.8097 \\
\hline 5 & 100 & 50 & 600 & $2.08 \cdot 10^{-4}$ & $2.09 \cdot 10^{-4}$ & 3.7349 & 1.7840 \\
\hline 6 & 100 & 60 & 600 & $2.08 \cdot 10^{-4}$ & $2.51 \cdot 10^{-4}$ & 3.7295 & 1.7607 \\
\hline 7 & 100 & 80 & 600 & $2.08 \cdot 10^{-4}$ & $3.34 \cdot 10^{-4}$ & 3.7157 & 1.7116 \\
\hline 8 & 100 & 120 & 600 & $2.08 \cdot 10^{-4}$ & $5.01 \cdot 10^{-4}$ & 3.6924 & 1.6337 \\
\hline 9 & 100 & 200 & 600 & $2.08 \cdot 10^{-4}$ & $8.35 \cdot 10^{-3}$ & 3.6602 & 1.5257 \\
\hline \multicolumn{6}{|c|}{$\Delta \delta_{\text {sat }}(\mathrm{ppm})$} & 0.2329 & 0.8376 \\
\hline \multirow{2}{*}{\multicolumn{6}{|c|}{$\mathrm{K}_{\mathrm{a}}(\mathrm{mol} / \mathrm{l})$}} & 1504 & 1295 \\
\hline & & & & & & $\pm 11 \%$ & $\pm 4 \%$ \\
\hline
\end{tabular}
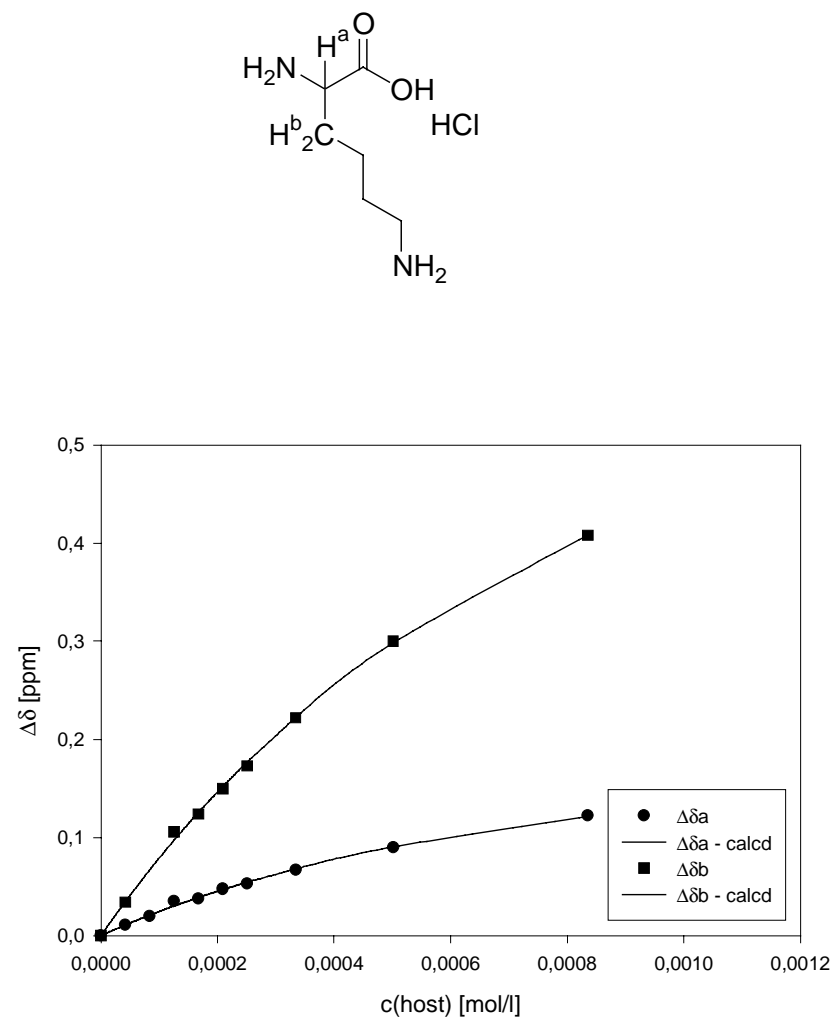


\section{NMR titration between Tweezer 1 and $(S)$-Lysinyl-(S)-lysinyl-(S)-leucinyl-(S)-valinyl-}

\section{(S)-phenylalaninyl-(S)-phenylalanine (KKLVFF)}

Host solution: $1.367 \mathrm{mg}\left(1.013^{-6} \mathrm{~mol}\right)$ host $\mathbf{1}$ in $650 \mu \mathrm{L}$ [25 mmol/1 Na $\mathrm{HPO}_{4} / \mathrm{NaH}_{2} \mathrm{PO}_{4}$ buffer $(\mathrm{pH} 7)$ in $\left.\mathrm{D}_{2} \mathrm{O}\right] /$ methanol- $d_{4}=1: 1 \mathrm{v} / \mathrm{v}$.

Guest solution: $1.107 \mathrm{mg}\left(9.883 \cdot 10^{-7} \mathrm{~mol}\right) \mathrm{KKLVFF} \cdot 3 \mathrm{TFA}$ in $2000 \mu \mathrm{L}$ [25 mmol/1 $\mathrm{Na}_{2} \mathrm{HPO}_{4} / \mathrm{NaH}_{2} \mathrm{PO}_{4}$ buffer $(\mathrm{pH} 7)$ in $\left.\mathrm{D}_{2} \mathrm{O}\right] /$ methanol- $d_{4}=1: 1 \mathrm{v} / \mathrm{v}$.

\begin{tabular}{cccccccc}
\hline Entry & $\begin{array}{c}\mathrm{V}_{\text {guest }} \\
(\mu \mathrm{L})\end{array}$ & $\begin{array}{c}\mathrm{V}_{\text {host }}(\mu \mathrm{L}) \\
(\mu \mathrm{L})\end{array}$ & $\begin{array}{c}\mathrm{V}_{\text {total }} \\
\left(\mu \mathrm{c}_{\text {guest }}\right. \\
(\mathrm{mol} / \mathrm{l})\end{array}$ & $\begin{array}{c}\mathrm{c}_{\text {host }} \\
(\mathrm{mol} / \mathrm{l})\end{array}$ & $\begin{array}{c}\delta_{\mathrm{a}} \\
(\mathrm{ppm})\end{array}$ & $\begin{array}{c}\delta_{\mathrm{b}} \\
(\mathrm{ppm})\end{array}$ \\
\hline 0 & 200 & 0 & 600 & $1.67 \cdot 10^{-4}$ & 0 & 2.9643 & 1.6809 \\
1 & 200 & 10 & 600 & $1.67 \cdot 10^{-4}$ & $3.51 \cdot 10^{-5}$ & 2.9351 & 1.6548 \\
2 & 200 & 20 & 600 & $1.67 \cdot 10^{-4}$ & $7.03 \cdot 10^{-5}$ & 2.9109 & 1.6097 \\
3 & 200 & 30 & 600 & $1.67 \cdot 10^{-4}$ & $1.05 \cdot 10^{-4}$ & 2.8995 & 1.6014 \\
4 & 200 & 40 & 600 & $1.67 \cdot 10^{-4}$ & $1.41 \cdot 10^{-4}$ & 2.8791 & 1.5766 \\
5 & 200 & 50 & 600 & $1.67 \cdot 10^{-4}$ & $1.76 \cdot 10^{-4}$ & 2.8652 & - \\
6 & 200 & 60 & 600 & $1.67 \cdot 10^{-4}$ & $2.11 \cdot 10^{-4}$ & 2.8607 & - \\
7 & 200 & 80 & 600 & $1.67 \cdot 10^{-4}$ & $3.81 \cdot 10^{-4}$ & - & 1.5556 \\
8 & 200 & 120 & 600 & $1.67 \cdot 10^{-4}$ & $4.22 \cdot 10^{-4}$ & 2.8505 & 1.5524 \\
9 & 200 & 200 & 600 & $1.67 \cdot 10^{-4}$ & $7.03 \cdot 10^{-4}$ & 2.8499 & - \\
\hline & & & & & $\Delta \delta_{\text {sat }}(\mathrm{ppm})$ & 0.1214 & 0.1365 \\
& & & & & $\pm 3 \%$ & $\pm 6 \%$ \\
\hline
\end{tabular}<smiles>CC(C)CC(NC(=O)C(CCC(N)C[PH2+])NC(=O)C(N)CCC(P)CN)C(=O)NC(C(=O)NC(Cc1ccccc1)C(=O)NC(Cc1ccccc1)C(=O)O)C(C)C</smiles>
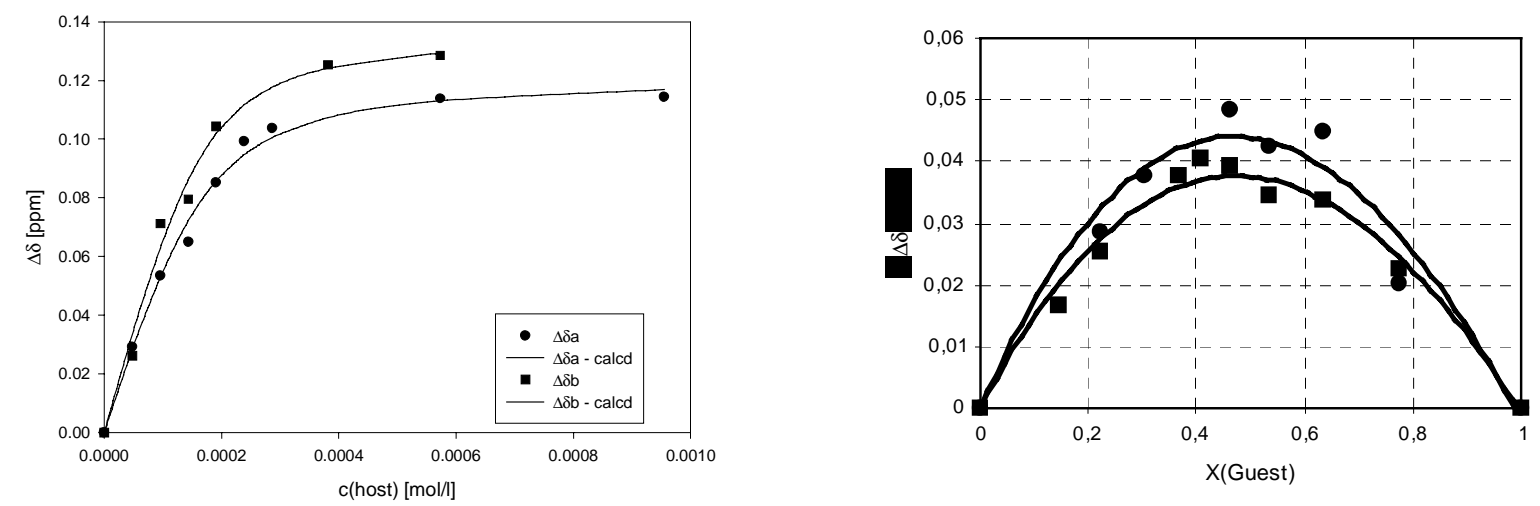


\section{NMR titration between tweezer 1 and $(S)$-Lysinyl-(S)-threoninyl-(S)-threoninyl-(S)-}

\section{lysine (KTTK)}

Host solution: $0.859 \mathrm{mg}\left(1.169^{-6} \mathrm{~mol}\right)$ host 1 in $650 \mu \mathrm{L} 25 \mathrm{mmol} / 1 \mathrm{Na}_{2} \mathrm{HPO}_{4} / \mathrm{NaH}_{2} \mathrm{PO}_{4}$ buffer $(\mathrm{pH} 7)$ in $\mathrm{D}_{2} \mathrm{O}$.

Guest solution: $0.837 \mathrm{mg}\left(1.026 \cdot 10^{-6} \mathrm{~mol}\right)$ KTTK·3TFA in $1750 \mu \mathrm{L} 25 \mathrm{mmol} / \mathrm{l}$ $\mathrm{Na}_{2} \mathrm{HPO}_{4} / \mathrm{NaH}_{2} \mathrm{PO}_{4}$ buffer (pH 7) in $\mathrm{D}_{2} \mathrm{O}$.

\begin{tabular}{|c|c|c|c|c|c|c|c|}
\hline Entry & $\begin{array}{l}V_{\text {guest }} \\
(\mu \mathrm{L})\end{array}$ & $\begin{array}{l}V_{\text {host }} \\
(\mu L)\end{array}$ & $\begin{array}{l}V_{\text {total }} \\
(\mu \mathrm{L})\end{array}$ & $\begin{array}{l}\mathrm{c}_{\text {guest }} \\
(\mathrm{mol} / \mathrm{l})\end{array}$ & $\begin{array}{c}\mathrm{c}_{\text {host }} \\
(\mathrm{mol} / \mathrm{l})\end{array}$ & $\begin{array}{c}\delta_{\mathrm{a}} \\
(\mathrm{ppm})\end{array}$ & $\begin{array}{c}\delta_{\mathrm{b}} \\
(\mathrm{ppm})\end{array}$ \\
\hline 0 & 175 & 0 & 600 & $3.42 \cdot 10^{-4}$ & 0 & 3.9847 & 1.8700 \\
\hline 1 & 175 & 10 & 600 & $3.42 \cdot 10^{-4}$ & $3.51 \cdot 10^{-5}$ & 3.9599 & 1.8366 \\
\hline 2 & 175 & 20 & 600 & $3.42 \cdot 10^{-4}$ & $7.03 \cdot 10^{-5}$ & 3.9425 & 1.8247 \\
\hline 3 & 175 & 30 & 600 & $3.42 \cdot 10^{-4}$ & $1.05 \cdot 10^{-4}$ & 3.9127 & 1.7949 \\
\hline 4 & 175 & 40 & 600 & $3.42 \cdot 10^{-4}$ & $1.41 \cdot 10^{-4}$ & 3.8917 & 1.7894 \\
\hline 5 & 175 & 50 & 600 & $3.42 \cdot 10^{-4}$ & $1.76 \cdot 10^{-4}$ & 3.8729 & 1.7793 \\
\hline 6 & 175 & 60 & 600 & $3.42 \cdot 10^{-4}$ & $2.11 \cdot 10^{-4}$ & 3.8536 & 1.7597 \\
\hline 7 & 175 & 80 & 600 & $3.42 \cdot 10^{-4}$ & $3.81 \cdot 10^{-4}$ & 3.8156 & 1.7290 \\
\hline 8 & 175 & 120 & 600 & $3.42 \cdot 10^{-4}$ & $4.22 \cdot 10^{-4}$ & 3.7684 & 1.7010 \\
\hline 9 & 175 & 200 & 600 & $3.42 \cdot 10^{-4}$ & $7.03 \cdot 10^{-4}$ & 3.6961 & 1.6085 \\
\hline \multicolumn{6}{|c|}{$\Delta \delta_{\text {sat }}(\mathrm{ppm})$} & $\begin{array}{c}0.4061 \\
\pm 5 \%\end{array}$ & $\begin{array}{l}0.4217 \\
\pm 16 \%\end{array}$ \\
\hline \multicolumn{6}{|c|}{$\begin{array}{r}\mathrm{K}_{\mathrm{a}}(\mathrm{mol} / \mathrm{l}) \\
(2: 1 \text { Komplex })\end{array}$} & $\begin{array}{c}6821 \\
\pm 18 \%\end{array}$ & $\begin{array}{r}4205 \\
\pm 45 \%\end{array}$ \\
\hline
\end{tabular}<smiles>CC(O)C(NC(=O)[C@@H](N)CCC(=O)NC(C(=O)N[C@@H](CC[C@H](C)CN)C(=O)O)C(C)O)C(=O)O</smiles>
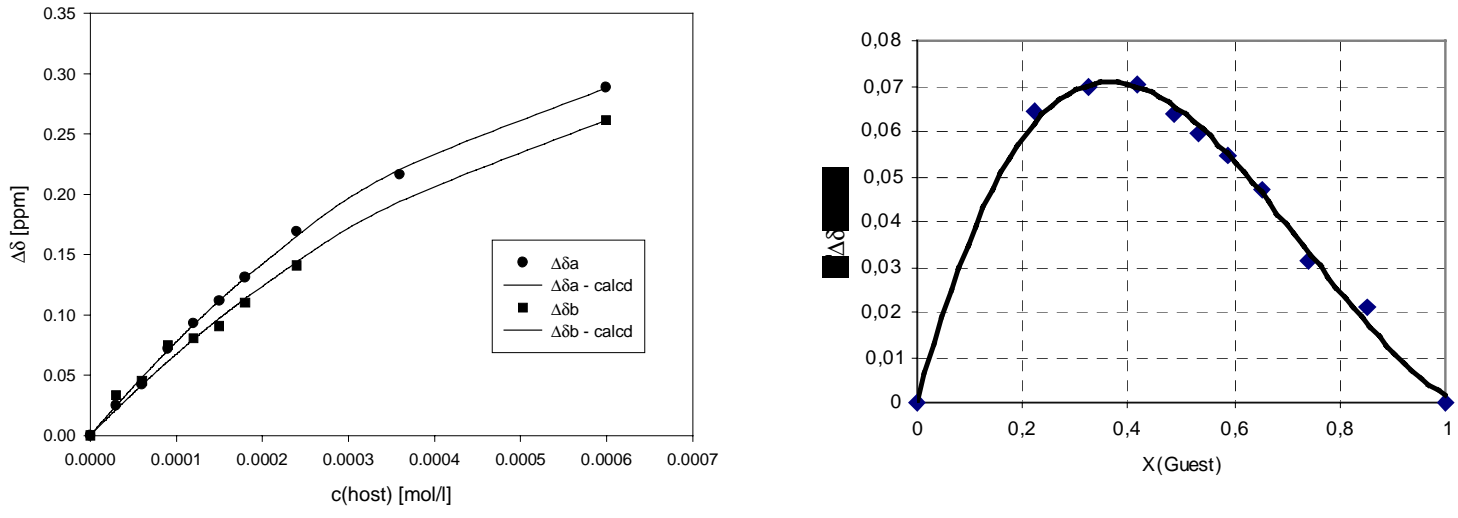


\section{Titration between tweezer 1 and $(S)$-Lysinyl-(S)-threoninyl-(S)-threoninyl-(S)-lysinyl-}

(S)-serine (KTTKS)

Host solution: $1.111 \mathrm{mg}\left(1.513^{-6} \mathrm{~mol}\right)$ host 1 in $650 \mu \mathrm{L} 25 \mathrm{mmol} / 1 \mathrm{Na}_{2} \mathrm{HPO}_{4} / \mathrm{NaH}_{2} \mathrm{PO}_{4}$ buffer $(\mathrm{pH} 7)$ in $\mathrm{D}_{2} \mathrm{O}$.

Guest solution: $0.724 \mathrm{mg}\left(8.001 \cdot 10^{-7} \mathrm{~mol}\right) \quad \mathrm{KTTKS} \cdot 3 \mathrm{TFA}$ in $750 \mu \mathrm{L} 25 \mathrm{mmol} / \mathrm{l}$ $\mathrm{Na}_{2} \mathrm{HPO}_{4} / \mathrm{NaH}_{2} \mathrm{PO}_{4}$ buffer ( $\left.\mathrm{pH} 7\right)$ in $\mathrm{D}_{2} \mathrm{O}$.

\begin{tabular}{|c|c|c|c|c|c|c|c|}
\hline Entry & $\begin{array}{l}V_{\text {guest }} \\
(\mu \mathrm{L})\end{array}$ & $\begin{array}{l}V_{\text {host }} \\
(\mu \mathrm{L})\end{array}$ & $\begin{array}{l}\mathrm{V}_{\text {total }} \\
(\mu \mathrm{L})\end{array}$ & $\begin{array}{c}\mathrm{C}_{\text {guest }} \\
(\mathrm{mol} / \mathrm{L})\end{array}$ & $\begin{array}{c}\mathrm{C}_{\text {host }} \\
(\mathrm{mol} / \mathrm{L})\end{array}$ & $\begin{array}{c}\delta_{\mathrm{a}} \\
(\mathrm{ppm})\end{array}$ & $\begin{array}{c}\delta_{\mathrm{b}} \\
(\mathrm{ppm})\end{array}$ \\
\hline 0 & 75 & 0 & 600 & $2.66 \cdot 10^{-4}$ & 0 & 3.9518 & 1.4881 \\
\hline 1 & 75 & 10 & 600 & $2.66 \cdot 10^{-4}$ & $1.94 \cdot 10^{-5}$ & 3.9318 & - \\
\hline 2 & 75 & 20 & 600 & $2.66 \cdot 10^{-4}$ & $3.88 \cdot 10^{-5}$ & 3.8848 & 1.1067 \\
\hline 3 & 75 & 30 & 600 & $2.66 \cdot 10^{-4}$ & $5.82 \cdot 10^{-5}$ & - & 1.0165 \\
\hline 4 & 75 & 40 & 600 & $2.66 \cdot 10^{-4}$ & $7.76 \cdot 10^{-5}$ & 3.8439 & 0.9121 \\
\hline 5 & 75 & 50 & 600 & $2.66 \cdot 10^{-4}$ & $9.70 \cdot 10^{-5}$ & 3.8204 & 0.7755 \\
\hline 6 & 75 & 60 & 600 & $2.66 \cdot 10^{-4}$ & $1.16 \cdot 10^{-4}$ & 3.7882 & 0.6000 \\
\hline 7 & 75 & 80 & 600 & $2.66 \cdot 10^{-4}$ & $1.55 \cdot 10^{-4}$ & 3.7746 & 0.4300 \\
\hline 8 & 75 & 120 & 600 & $2.66 \cdot 10^{-4}$ & $2.33 \cdot 10^{-4}$ & 3.7136 & 0.1300 \\
\hline 9 & 75 & 180 & 600 & $2.66 \cdot 10^{-4}$ & $3.49 \cdot 10^{-4}$ & 3.6722 & - \\
\hline \multicolumn{6}{|c|}{$\Delta \delta_{\text {sat }}(\mathrm{ppm})$} & $\begin{array}{c}0.3903 \\
\pm 8 \%\end{array}$ & $\begin{array}{r}2.620 \\
+15 \%\end{array}$ \\
\hline \multirow{2}{*}{\multicolumn{6}{|c|}{$\begin{array}{r}\mathrm{K}_{\mathrm{a}}(\mathrm{mol} / \mathrm{l}) \\
(2: 1 \text { complex })\end{array}$}} & 4998 & 3307 \\
\hline & & & & & & $\pm 24 \%$ & $\pm 33 \%$ \\
\hline
\end{tabular}

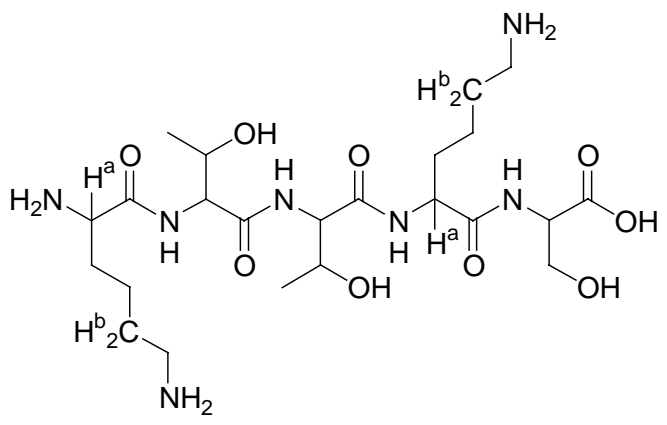
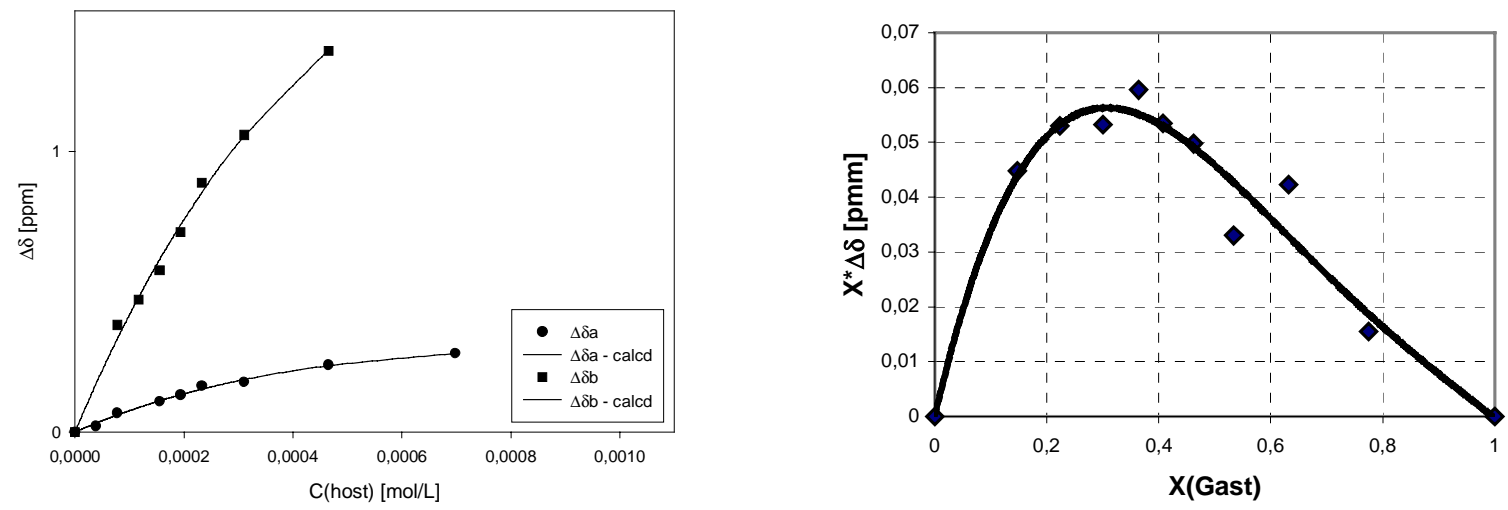
ITC measurements. ITC experiments were carried out on a Microcal VP-ITC. Titrations were performed at $298 \mathrm{~K}$ with a reference power of $10 \mu \mathrm{Cal} / \mathrm{s}$. The host concentration in the cell was set at $0.5 \mathrm{mM}$, the guest was added through the syringe $(7.5 \mathrm{mM})$ in $10 \mu \mathrm{L}$ steps $(5$ $\mu \mathrm{L}$ for the first step) during $8 \mathrm{~s}$ (4 s for the first step). $360 \mathrm{~s}$ spacings between the single titration steps were applied.

ITC titration of host $1\left(5.0 \cdot 10^{-4} \mathrm{M}\right)$ with acetyl- $(S)$-lysine methyl ester hydrochloride $\left(7.5 \cdot 10^{-}\right.$ $\left.{ }^{3} \mathrm{M}\right)$ in water.

\begin{tabular}{lllll}
\hline Nr. & $\Delta \mathrm{H}[\mathrm{kJ} / \mathrm{mol}]$ & $K_{\mathrm{a}}\left[\mathrm{M}^{-1}\right]$ & $\mathrm{n}$ & $-\mathrm{T} \Delta \mathrm{S}[\mathrm{kJ} / \mathrm{mol}]$ \\
\hline 1 & $-27.77 \pm 0.27$ & $1.45 \cdot 10^{4} \pm 3.8 \cdot 10^{2}$ & $0.647 \pm 0,005$ & -4.10 \\
2 & $-26.41 \pm 0.16$ & $1.70 \cdot 10^{4} \pm 3.3 \cdot 10^{2}$ & $0.735 \pm 0.003$ & -2.35 \\
\hline
\end{tabular}
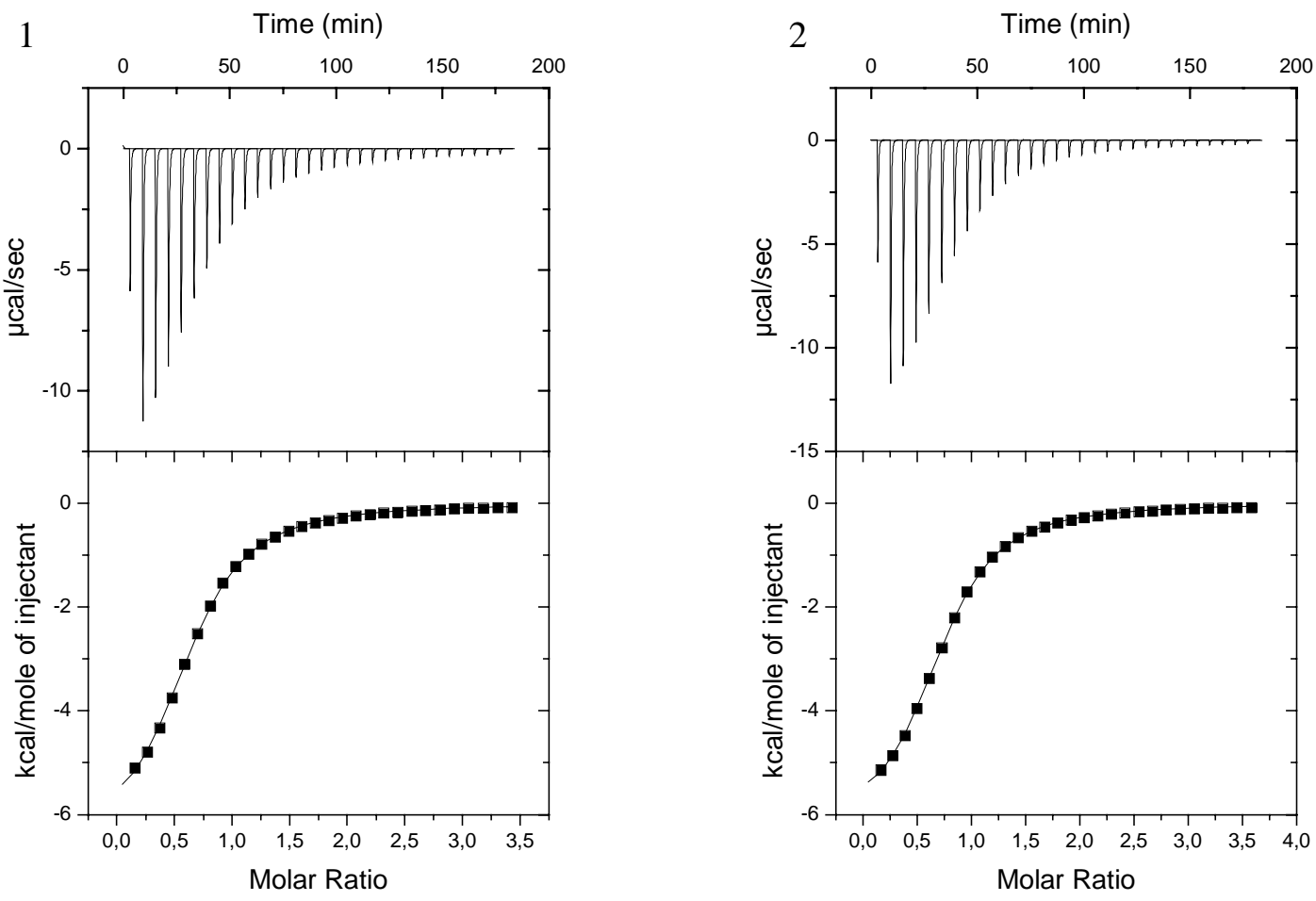

NMR Titrations with solvents. 10, 100, 1000, 10000 and 10900 equivalents of deuterated DMSO were added to $600 \mu \mathrm{L}$ of an equimolar solution containing host 1 and acetyl- $(S)$-lysine methyl ester hydrochloride $\left(2 \cdot 10^{-4} \mathrm{M}\right)$, as well as to a reference solution containing only acetyl-(S)-lysine methyl ester hydrochloride (same concentration) in $25 \mathrm{mM}$ phosphate buffer (pH 7) in deuterated water. The small chemical shift changes in the reference solution were subtracted from the larger effects in the host/guest mixture. These results are given in the table below as $\Delta \delta_{\text {obs. }}$ values. To compare the effect of acetonitrile and methanol, $200 \mu \mathrm{L}$ deuterated acetonitrile or deuterated methanol were added to the above-mentioned samples with 10 and 100 equivalents (which had formerly shown no effect). 


\begin{tabular}{llll}
\hline added solvent & equivalents & $\Delta \delta_{\text {obs. }}\left({ }^{\varepsilon} \mathrm{CH}_{2}\right)$ & $\Delta \delta_{\text {obs. }}\left({ }^{\beta} \mathrm{CH}_{2}\right)$ \\
\hline DMSO- $d_{6}$ & 10 & not visible (broad signal) & -0.52 \\
DMSO- $d_{6}$ & 100 & not visible (broad signal) & -0.47 \\
DMSO- $d_{6}$ & 1000 & not visible (broad signal) & -0.13 \\
DMSO- $d_{6}$ & 10000 & -0.01 & -0.01 \\
DMSO- $d_{6}$ & 10900 & $<-0.01$ & $<-0.01$ \\
acetonitrile- $d_{3}$ & 16000 & $<-0.01$ & $<-0.01$ \\
methanol- $d_{4}$ & 20600 & -0.35 & -0.10 \\
\hline
\end{tabular}

\section{References}

[1] J. Panitzky, dissertation thesis, Universität Essen (Essen), 2001.

[2] M. Kamieth, dissertation thesis, Universität Essen (Essen), 1998.

[3] F.-G. Klärner, U. Burkert, M. Kamieth, R. Boese, J. Benet-Buchholz, Chem. Eur. J. 1999, 5, 1700-1707.

[4] P. Job, Compt. Rend. 1925, 180, 928-930. 